\title{
FิIIASA
}

\section{Dynamics of Energy \\ Technologies and \\ Global Change}

Arnulf Grübler, Nebojša Nakićenović, and David G. Victor

RR-99-7

August 1999 



\section{DYNAMICS OF ENERGY TECHNOLOGIES AND GLOBAL CHANGE}

Arnulf Grübler

International Institute for Applied Systems Analysis

Laxenburg, Austria

Nebojša Nakićenović

International Institute for Applied Systems Analysis

Laxenburg, Austria

David G. Victor

Council of Foreign Relations, New York, NY, USA

RR-99-7

August 1999

Reprinted from Energy Policy, Volume 27, pp. 247-280, 1999.

International Institute for Applied Systems Analysis, Laxenburg, Austria Tel: +432236807 Fax: +43223673148 E-mail: publications@iiasa.ac.at 
Research Reports, which record research conducted at IIASA, are independently reviewed before publication. Views or opinions expressed herein do not necessarily represent those of the Institute, its National Member Organizations, or other organizations supporting the work.

Reprinted with permission from Energy Policy, Volume 27, pp. 247-280, 1999. Copyright (c) 1999, Elsevier Sciene Ltd.

All rights reserved. No part of this publication may be reproduced or transmitted in any form or by any means, electronic or mechanical, including photocopy, recording, or any information storage or retrieval system, without permission in writing from the copyright holder. 


\title{
Dynamics of energy technologies and global change
}

\author{
Arnulf Grübler ${ }^{\mathrm{a}}$, Nebojša Nakićenovića ${ }^{\mathrm{a}}$, David G. Victor ${ }^{\mathrm{b}, *}$ \\ ${ }^{3}$ Entironmentally. Compatible Energy Strategies Project, International Institute for Applied Systemis Analysis, A-2361 Laxenburg, Austria \\ ${ }^{\mathrm{h}}$ Council on Foreign Relations, 58 E 68th Street. New York. NY 10021 USA
}

Received 13 November 1998

\begin{abstract}
Technological choices largely determine the long-term characteristics of industrial society, including impacts on the natural environment. However, the treatment of technology in existing models that are used to project economic and environmental futures remains highly stylized. Based on work over two decades at IIASA, we present a useful typology for technology analysis and discuss methods that can be used to analyze the impact of technological changes on the global environment, especially global warming. Our focus is energy technologies, the main source of many atmospheric environmental problems. We show that much improved treatment of technology is possible with a combination of historical analysis and new modeling techniques. In the historical record, we identify characteristic "learning rates" that allow simple quantified characterization of the improvement in cost and performance due to cumulative experience and investments. We also identify patterns, processes and timescales that typify the diffusion of new technologies in competitive markets. Technologies that are long-lived and are components of interlocking networks typically require the longest time to diffuse and co-evolve with other technologies in the network; such network effects yield high barriers to entry even for superior competitors.

These simple observations allow three improvements to modeling of technological change and its consequences for global environmental change. One is that the replacement of long-lived infrastructures over time has also replaced the fuels that power the economy to yield progressively more energy per unit of carbon pollution - from coal to oil to gas. Such replacement has "decarbonized" the global primary energy supply $0.3 \%$ per year. In contrast, most baseline projections for emissions of carbon, the chief cause of global warming, ignore this robust historical trend and show little or no decarbonization. A second improvement is that by incorporating learning curves and uncertainty into micro scale models it is possible to endogenously generate patterns of technological choice that mirror the real world. Those include S-shaped diffusion patterns and timescales of technological dynamics that are consistent with historical experience: they also include endogenous generation of "surprises" such as the appearance of radically new technologies. Third. it is possible to include learning phenomena stylistically in macro-scale models; we show that doing so can yield projections with lessened environmental impacts without necessarily incurring negative effect on the economy. Arriving on that path by the year 2100 depends on intervening actions, such as incentives to promote greater diversity in technology and lower barriers to entry for new infrastructures that could accelerate historical trends of decarbonization. C. 1999 Elsevier Science Ltd. All rights reserved.
\end{abstract}

Keywords: Endogenous technological change: Modeling: Global warming

\section{Introduction}

Changes in products, devices, processes and practices - technology $y^{1}$ - largely determine the development and consequences of industrial society. Technology has allowed hunger to decline while the world population more than doubled since 1950 and cropland rose by only

\footnotetext{
*Corresponding author

"A broad definition of "technology" is adopted here because it is difficult to separate the (economic and social) importance of physical artifacts from the social and institutional processes that put those artifacts into practice. See, eg. Freeman (1982 1989).
}

one-third (Hayami and Ruttan, 1985). The appearance of radically new technologies has eliminated some environmental problems while creating new ones - automobiles extinguished horses and manure stench from the road but now cause pervasive urban smog. Incremental adjustments to existing technologies have also improved environmental performance. Examples include the addition of catalytic converters to automobiles, which partially cut smog and forced fuel suppliers to get the poisonous lead out of gasoline. Even small technological changes have had radical effects when compounded over many years - thousands of hardware and managerial changes allow today's airlines to deliver a seat-kilometer 
of service by burning less than half the fuel required three decades ago.

Despite the centrality of technology, analytical techniques that are useful for analyzing technological change and its impacts remain embryonic. We argue that it is possible to do better by simultaneously applying a multitude of techniques developed and refined by colleagues and ourselves over two decades at the International Institute for Applied Systems Analysis (IIASA). Our focus is the impact of technology on "global change" - the local, regional and worldwide effects of industrial society on the environment. We show that typical rates and patterns of technological change can be identified in history, and new analytical techniques and increased computational power allow more appropriate ("endogenous") modeling of technological change. Long-term technological forecasting still remains elusive; however, historical analysis and improved numerical modeling, together, can sharply increase the ability to anticipate technological changes and their environmental impacts.

Economic theory, historical evidence, and (neoclassical) growth models confirm that advancing technological knowledge is the most important single factor that contributes to long-term productivity and economic growth. ${ }^{2}$ Yet, in most models of long-term economic development and environmental change, technology continues to be treated as a quantity exogenous to the economy and society at large. Typically the only endogenous mechanism of technological change in existing models is progressive resource depletion, such as running out of oil, which results in increasing costs of resource extraction that favor more expensive, but resource-frugal technologies. (Often these are modeled as "backstop" technologies, a term coined by Nordhaus (1973).) However, technological change triggered by resource constraints is somewhat inconsistent with historical experience. (See Barnett and Morse (1967) and, for a current review of hydrocarbon resources, see Rogner (1997).)

Although analysts agree that technological change is crucial, in practice most analysis proceeds as if most

\footnotetext{
2For reviews see Metcalfe (1987) and Freeman (1994). For empirical evidence from economic history see Maddison $(1991,1995)$ and Mokyr (1990). For a review of the treatment of technological change as "residual" of long-run productivity growth see Griliches (1996). The two classical papers sifting out the impact of technological change on productivity growth based on neoclassical production function models are: Tinbergen (1942) and Solow (1957). For instance, in Solow's calculations advances in knowledge (technology) account for $85 \%$ of economic growth per capita, and only $15 \%$ is accounted for by increases in capital. Alternative approaches. particularly those within "new growth theory" have extended the classical production function by adding an endogenous "knowledge" stock variable, measurement of which, however, remains elusive (cf. Romer, 1990). As a rule, the factors entering a production function (capital. labor, knowledge, technology) are treated as independent of each other. This assumption is criticized by Abramovitz (1993).
}

technological change cannot be anticipated and modeled. Some studies largely ignore technological change; thus, by design, they typically yield Malthusian projections of starvation and ecological catastrophes as populations and economies grow while not using finite resources more efficiently (Meadows et al, 1972, 1992). Many studies include only marginal and gradual technological changes, often through an aggregate trend parameter - such as the annual rate of efficiency improvement - that is (exogenously) tuned according to historical experience. That technique is compatible with the highly aggregated macroeconomic modeling tools that are commonly employed in global change studies. Such models do not represent the selection of particular technologies and thus are only able to include technological changes that are marginal extensions of the present. Yet the historical record is abundant with radical technological changes. Even models in the tradition of systems engineering - where detailed information on technological costs and performance is used to calculate least cost technological systems - have largely failed to address technological change. Some ignore changes in costs and performance (and thus implicitly assume that technologies are static). Most impose those changes exogenously but have no mechanism - other than the intuition of the modeler - to ensure that the assumptions imposed are plausible and internally consistent. Very few systems models have included rudimentary endogenous mechanisms of technological change, such as learning curves. (For exceptions see Messner et al (1996), Fragnière and Haurie (1995) and Messner (1997); see also Nordhaus and van der Heyden (1993) and the discussion below.) Yet only rarely are those models linked with macroeconomic tools to allow systematic analysis of the technological aspects of global change problems. Here we present one of the first such applications of linked models.

Treatment of technological change is especially difficult yet crucial for analysis of the impacts of industrial society over long time periods - decades and centuries. On those time scales, which are characteristic of the environmental issues that constitute global change, even small technological changes can compound into radically different technological systems and environmental effects. Because the timescales are long and the existing analytical techniques are imperfect, typically analysts bound a range of plausible futures and policy options with scenarios. Those scenarios are built with the same models that poorly represent technological change, and thus extant scenarios also typically ignore technological change or mechanically extrapolate past trends into the future. (For a recent review see Alcamo et al (1994).) Some scenario-builders adopt radical visions for technologies that will be invented and adopted (eg, Lazarus et al, 1993), which helps to define boundaries for possible futures but offers little insight into the costs and probabilities of those utopic extremes. Indeed, extreme low 
and high scenarios for emissions of carbon dioxide - which vary from about $2 \mathrm{GtC}$ (gigatons, $10^{15}$ grams, of elemental carbon) to more than $30 \mathrm{GtC}$ in the year 2100 - differ mainly due to their underlying assumptions about technology.

We argue that technological futures are neither opaque nor unbounded. Because global change problems are numerous, we focus on the main source of many environmental problems: the combustion of fossil fuels. Because technological changes can be most dramatic over the long term, we focus on greenhouse warming, which is principally caused by the accumulation of carbon dioxide released during the combustion of fossil fuels over many decades. With the use of comprehensive historical statistics compiled at IIASA, we argue that three robust attributes of energy technologies and their greenhouse impacts are evident in the historical record. (1) Typical improvements in cost and performance of new technologies due to "learning" can be identified. (2) Dynamic competition between technologies to provide energy services, such as mobility, yields predictable patterns for the entry and exit of technologies in competitive markets. (3) Network effects and technological interdependence such as between petroleum refineries, pipelines, gas stations, and gasoline-powered automobiles result in characteristic patterns of technological co-evolution. We argue that these three attributes make possible the development of models with realistic and endogenous treatment of technological change, which we demonstrate rigorously at the micro scale and stylistically for the world's entire energy system. In sum, technological assessment is still imperfect; some aspects of technological futures, especially related to the timing and character of radical technological inventions, are still shrouded in mystery. But better analysis and modeling of the stages of technological change that follow invention is possible. Before we argue how, we present a consistent typology that helps to classify the processes at work.

\section{A typology for technology analysis}

Technological change is a complex process. A simple typology helps to identify the key mechanisms, concepts and measures. We distinguish six stages (Table 1) in the life-cycle of a technology. Following Shumpeter (1934) and Freeman (1982/1989) we distinguish between invention, which is the creation of an idea, and innovation,

Table 1

Stylized stages of technological development and typical characteristics.

\begin{tabular}{|c|c|c|c|c|}
\hline Stage & Mechanisms & Cost & $\begin{array}{l}\text { Commercial } \\
\text { Market share }\end{array}$ & Learning Rate \\
\hline Invention & $\begin{array}{l}\text { Secking and stumbling upon new } \\
\text { ideas; breakthroughs; basic research }\end{array}$ & $\begin{array}{l}\text { High, but difficult to } \\
\text { attribute to a particular } \\
\text { idea or product }\end{array}$ & $0 \%$ & $\begin{array}{l}\text { Unuble to express in } \\
\text { conventional learning } \\
\text { curve }\end{array}$ \\
\hline Innovation & $\begin{array}{l}\text { Applied research. development and } \\
\text { demonstration (RD\&D) projects }\end{array}$ & $\begin{array}{l}\text { High. increasingly focused } \\
\text { on particular promising } \\
\text { ideas and products }\end{array}$ & $0 \%$ & $\begin{array}{l}\text { Unable to express in } \\
\text { conventional learning } \\
\text { curve; high (perhaps } \\
>50 \% \text { ) in learning } \\
\text { curves modified to } \\
\text { include RD\&D (see text) }\end{array}$ \\
\hline $\begin{array}{l}\text { Niche market } \\
\text { commercialization }\end{array}$ & $\begin{array}{l}\text { Identification of special niche } \\
\text { applications: investments in field } \\
\text { projects: "learning by doing": close } \\
\text { relationships between suppliers } \\
\text { and users }\end{array}$ & $\begin{array}{l}\text { High, but declining } \\
\text { with standardization of } \\
\text { production }\end{array}$ & $0-5 \%$ & $20-40 \%$ \\
\hline Pervasive diffusion & $\begin{array}{l}\text { Standardization and mass production; } \\
\text { economies of scale; building of } \\
\text { network effects. }\end{array}$ & Rapidly declining & $\begin{array}{l}\text { Rapidly rising } \\
(5-50 \%)\end{array}$ & $10-30 \%$ \\
\hline Saturation & $\begin{array}{l}\text { Exhaustion of improvement potentials } \\
\text { and scale economies; arrival of more } \\
\text { efficient competitors into market; } \\
\text { redefinition of performance } \\
\text { requirements }\end{array}$ & Low, sometimes declining & $\begin{array}{l}\text { Maximum } \\
\text { (up to } 100 \% \text { ) }\end{array}$ & $\begin{array}{l}0 \% \text { (sometimes positive } \\
\text { due to severe } \\
\text { competition) }\end{array}$ \\
\hline Senescence & $\begin{array}{l}\text { Domination by superior competitors; } \\
\text { inability to compete because of } \\
\text { exhausted improvement potentials }\end{array}$ & Low, sometimes declining & Declining & $\begin{array}{l}0 \% \text { (sometimes } \\
\text { positive due to severe } \\
\text { competition) }\end{array}$ \\
\hline
\end{tabular}

Site: Also shown. in the right column, are three terms often used when classifying technologies that are marked by substantially different relative performance at a given moment in time. Much of technological analysis for purposes of assessing environmental effects is aimed at examining which new (radical and incremental) technologies will achieve what speed and level of penetration in commercial markets. 
which is marked by the first practical application of an invention. Many inventions are the product of fundamental and applied research. Often innovation takes the form of development and demonstration projects in an industrial laboratory. This definition of innovation is narrow, although often the label is applied broadly to the entire process of commercialization that follows the first practical application.

Following development and demonstration, the useful services of a new technology are typically first employed in niche markets, where a novel technology has substantial performance advantages over existing technologies. The first commercialization in niche markets allows suppliers and users to "learn by doing" and "learn by using" which leads to further improvements in performance and cost. Use in a wider array of markets, or pertasive diffusion, follows. When those markets are exhausted saturation is the result. Senescence follows when a better (new) competitor takes market share or redefines performance requirements.

Of all the aspects of technological development, the process of invention is least well understood, and even less well predicted. The inventor's mind, which must deviate from predictable conventions to discover novelty, is intrinsically difficult to model and anticipate. Even rewards from invention may play only a small role, especially in the generation of radically new concepts and devices. As the popular book on John Harrison's invention of the accurate marine chronometer demonstrates, high hurdles face the person who defies convention and then seeks recognition and returns from radical invention (Sobel, 1995).

The supply of inventions is also difficult to model because it is loosely related to the background state of knowledge - what some have called "knowledge stock" (Romer, 1986, 1990). But quantitative measures of useful knowledge, and their exact relationship to invention, are murky. Similarly important but poorly understood is the contribution of basic research.

For the other stages of technological change - from innovation through senescence - it is increasingly possible to make systematic observations and to model the processes at work, which are the tasks for the rest of this essay. Investments needed to yield innovations and viable commercial products from an invention are principally governed by market competition. Commercialization of a technology often requires large organizations and uniformity, which further increases the capacity of analysts to model relationships between inputs and outputs.

Like bacteria vying for scarce food, the evolution of technology is a competitive process. In many fields the cost of stumbling and searching for new ideas is relatively low and thus the supply of inventions is abundant; thoughts and talk are cheap. But the Darwinian selection mechanisms are stringent and few ideas ever take form outside the laboratory in commercial markets.
Investments needed to sustain a technology in its early, pre-competitive stages are made because there is hope of later returns. Once competitive, relative performance and costs govern success, which can be measured by market share. Indeed, these three indicators - performance, costs and market share - are useful measures of a technology's stage of development. Fig. 1 shows investment cost data for ten types of electricity generation technologies, drawn from IIASA's comprehensive energy technology database (CO2DB) (Messner, 1996; Schäfer et al, 1992; Messner and Strubegger, 1991). Technologies that are already in pervasive diffusion and saturation (eg, conventional fossil fuel electricity generating plants) are, as expected, less costly than those found only in niche markets (eg, photovoltaic cells).

The variance in investment cost for all technologies in Fig. 1 is high because capital requirements and performance depend on many local factors. Installing the least costly coal-fired electricity plants at ideal sites without pollution control equipment costs about US\$500 per kilowatt of generating capacity $(\mathrm{kW}(\mathrm{e}))$; typical costs for such plants are double that value, and modern plants with sulfur- and nitrogen-removal are typically twice again as expensive (US\$2000 / $\mathrm{kW}(\mathrm{e})$ ). (For a more detailed assessment of power plant cost distributions see Strubegger and Reitgruber (1995).) Niche markets are born in the long tails and when performance requirements change. Often new technologies provide a new service or function that is not possible or cost-effective with the old technologies. Examples include the precision of digital clocks compared with their analog counterparts, the speed and range of jet airplanes over pistonpowered models, and the affordability of solar photovoltaic power in remote mountain huts and road signs where wire connections to the conventional electric grid would be much costlier. Fear of global warming could redefine the performance requirements for electricity generation and thus create niche markets for low carbon electricity production. Removing and disposing of $\mathrm{CO}_{2}$ from flue gases would double or triple the cost of conventional fossil fuel-fired electricity plants, but solar, nuclear, and zero-carbon biomass could be largely unaffected and thus become more competitive.

Fig. 1 labels the ten technologies with useful commonsense terms that reflect the differences in cost, market share, and stage of technological development. "Mature" technologies have reached pervasive diffusion and have well-known characteristics; often they can change or improve under competitive pressure, but in general performance and costs are stable. "Incremental" technologies are found in niche markets - they are more costly but offer some performance advantages and the potential for significant cost reduction with continued investment. The rates and direction of such performance and cost improvements in incremental technologies can be anticipated. Commercial enterprises can envision the 


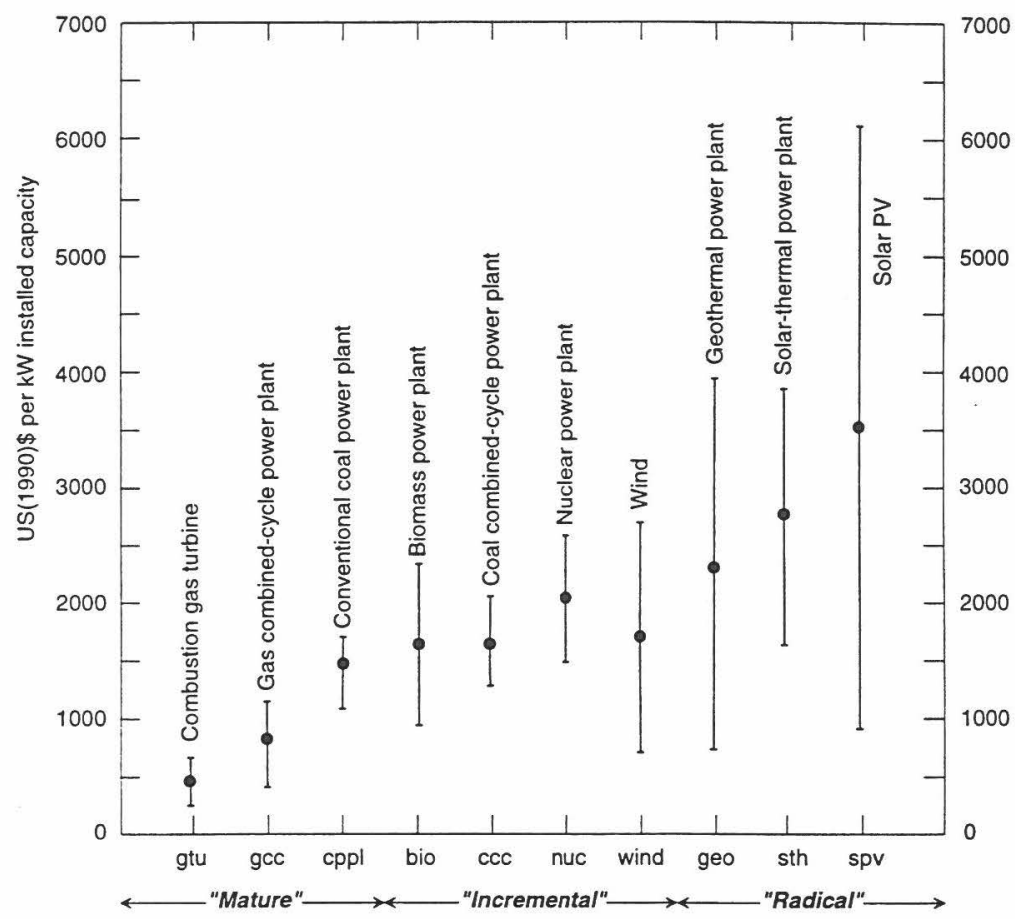

Fig. 1. Cost of selected electricity-generating technologies. Values (mean plus/minus one standard deviation) taken from IIASA's comprehensive technology database (CO2DB). Data are for approximately ceteris paribus conditions (eg, coal plants include de-SO $\mathrm{S}_{x}$ and de-NO $\mathrm{N}_{x}$ equipment). Mature technologies in widespread use have lower costs with lower variance: the costs of radical new technologies are higher and more variable. Variability of costs is also an indicator of the uncertainty of technology costs. Radical technologies are little tried and their potentials for cost reductions are uncertain, and thus so are estimates of their costs.

Source: Strubegger and Reitgruber (1995).

possibilities and modalities for better performance of a technology that is compatible with and incremental to existing technological systems, especially as market conditions change. "Radical" technologies are more uncertain, both in their potentials for improvement and in whether they will arrive on commercial markets at all. But the radical technology can also yield radical improvements in performance and cost - often by a factor of 10 or more. By definition, the radical technology is not widely employed, and thus only a small slice of its (potential) diffusion history can be observed.

The stages of technological development are distinguished by the mechanism at work, not time. For a completely new technology it is possible to identify a beginning or particular stage change, such as the birth of an idea or the first commercial sale. But mature, existing technologies can be the host for all stages of technological change simultaneously. Automobiles today, for cxample. are the site for the incorporation of basic research on modeling of complex systems into the invention of intelligent transportation systems that could, if the technology is successful, optimize road traffic flows, akin to air traffic control but without human intermediaries. Innovations in automobile technology include long-distance electric-powered vehicles. On-board navigation systems - with local maps updated by global positioning system, and limited capacity to optimize and direct trips - already exist in commercial niche markets, such as high-end rental cars designed for customers with poor local knowledge or strong desire to demonstrate technical prowess. The road data system (RDS), which transmits limited textual information and traffic updates, is in pervasive diffusion in Western Europe - virtually all new car radios are equipped, and all FM stations broadcast the necessary signals. The car radio itself is an example of saturation - practically $100 \%$ of new cars have one installed either by the factory or in the immediate after market.

In short, even as a technological system enters into and diffuses throughout a market, there is pervasive change within the system. The basic innovation that creates a new radical technology is followed by incremental 
changes that accrete around the basic innovation, which leads to improved performance and reduced costs. Like the development of science itself, portrayed by Lakatos (1970), the core defines the basic functions of the technology - it attracts compatible incremental changes and deters radical incompatible change. New technologies arise from within the economic system, but truly radical changes rarely come from the existing core. The process of innovation requires investments in innovations well before a new technology becomes really competitive and profitable. It also requires continued investments to further a technology's performance and to lower its costs to sustain successful diffusion. The process, if modeled in its details, is enormously complicated. Thus the approach in this paper is first to identify some basic patterns in the historical record that help to guide modeling and scenario building.

We use the term "technology" broadly. It denotes not only physical devices but also production knowledge and processes, which typically combine physical equipment, ideas and even social institutions (eg, the Ford method of production via standardization and assembly line). The term "technology" is also used to denote a system of related hardware or production processes (eg, the "automobile"). Like a fractal, new layers of activity become visible as one looks closely at a technological system, but basic patterns and processes remain similar. Even the mundane windshield wiper, which is part of the automobile's technological system, is the technological amalgam of rubber blades, airfoils that hold the blades in place at high airspeed, windshield-washing mechanisms, heating and delay timers, and microprocessor controls. Each component has been the site of change, and thus the technological system as a whole has also changed.

In this essay we examine both components and technological systems. When analyzing the environmental effects of technology it is usually crucial to examine particular technologies or processes, which ultimately determine environmental impacts. For example, the technological components of today's automobile are unlike those of the 1930s, and the environment is much better for the change. Emissions of carbon monoxide, nitrogen oxides and hydrocarbons totaled some $100 \mathrm{~g}$ per vehicle-km in the 1920s; today they have declined to only $2 \mathrm{~g}$ (Grübler, 1998). Part of the change reflects the collective effect of many technological changes to yield more complete combustion and higher efficiency. Automobile engine efficiencies in the 1920s were typically around $10 \%$, a value that has doubled today, thus halving energy use per $\mathrm{km}$ driven. Lower pollution is also a consequence of specific pollution control technologies, such as catalytic converters. Although environmental impacts are determined by particular technologies, we show that the selection of technologies is partially governed by attributes of the system, such as the availability of necessary infrastructures and other technological interdepen- dencies. For example, hydrogen fuel cell vehicles could allow practically zero emissions of air pollution, including carbon dioxide, but such technologies will not be viable without complementary hydrogen production and distribution technologies and infrastructures.

\section{Historical view of technological change}

The systematic definition of stages and mechanisms of technological change helps to identify fundamental attributes of technological change in the historical record and thus improve technological analysis and scenario building. For two decades, scientists at IIASA have compiled historical data on all major energy technologies for particular markets, nations, regions and the globe (Marchetti and Nakićenović, 1979; Nakićenović, 1984; Marchetti, 1988; Ausubel et al, 1988; Grübler, 1990; Grübler and Nakićenović, 1991; Nakićenović, 1994; Grübler, 1996). Those data help identify three robust attributes of technological change: (1) reductions in cost and improvements in performance through learning; (2) regular patterns of dynamic competition between technologies; and (3) the co-evolution of long-lived infrastructures and technological clusters due to "network effects" - the externalities and synergisms that make it costly for any single component to be incompatible with the whole.

\subsection{Learning}

The performance and productivity of individual technologies and technological systems typically increases as organizations and individuals gain experience with them. Long-studied in human psychology, technological learning phenomena were first described for the aircraft industry by Wright (1936), who reported that unit labor costs in air-frame manufacturing declined significantly with accumulated "experience", measured as cumulative production (output). Technological learning has since been analyzed empirically for numerous manufacturing and service activities (eg, ship building, petrochemicals, steam and gas turbines, farming of broiler chickens). Learning concepts have also been applied in a wide range of human activities, such as the success rates of new surgical procedures, productivity in kibbutz farming, and reliability of nuclear plant operation (Argote and Epple, 1990). In economics, "learning by doing" and "learning by using" have been highlighted since the early 1960s (Arrow, 1962; Rosenberg, 1982).

Learning phenomena are generally described in form of "learning" or "experience" curves, which typically show the decline in unit costs of production as experience is gained. Because learning depends on accumulation of actual experience and not just on the passage of time, learning curves generally take the form of a power function where unit costs decrease exponentially as a function 


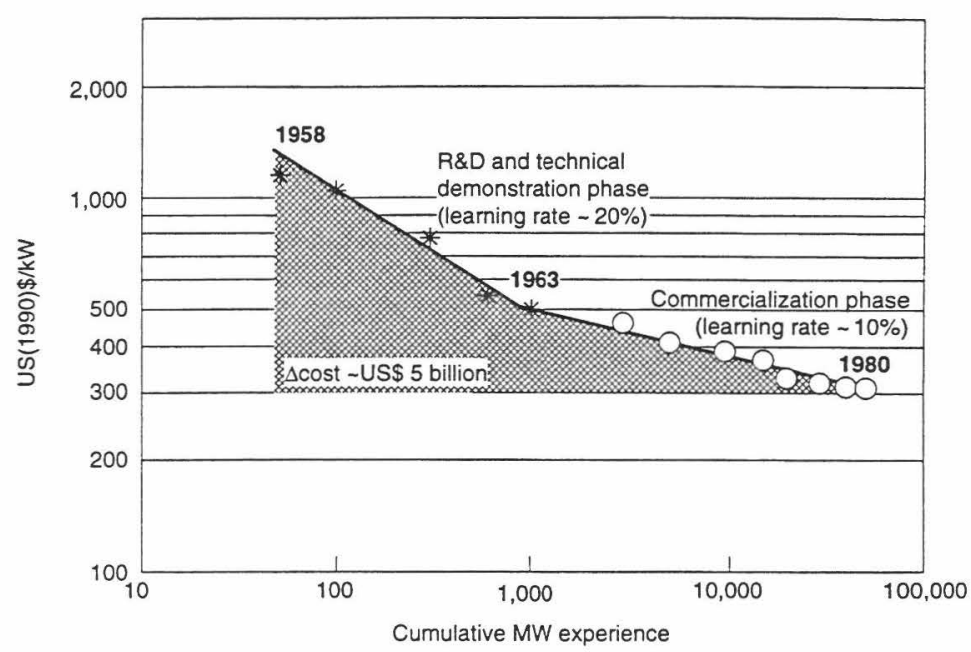

Fig. 2. Learning curve for gas turbines. Costs declined rapidly ( $20 \%$ per doubling of installed capacity) when the technology was in the "innovation" stage and learning was enhanced through applied research and development (R\&D). Costs continued to decline, but at a slower rate ( $\sim 10 \%$ per doubling) when the technology was commercialized in niche markets, such as through demonstration projects. The incremental investment for this technology - from first application of the technology to electricity generation until the technology was fully competitive - was approximately USS 5 billion. Data are only for one major firm (GE).

Source: data adapted from MacGregor et al (1991).

of cumulative output. Other measures include cumulative investments, installed hardware, or other proxies for "experience". The resulting curve is often plotted on logarithmically scaled axes so that it becomes a straight line. The learning rate - the slope of the line - is the percentage decline in costs per doubling of accumulated experience. Because each successive doubling requires more production volume, such straight-line plots should not be misunderstood to imply that "linear" progress can be maintained indefinitely. The potential for cost reductions becomes increasingly exhausted as the technology matures.

The mechanisms for learning by doing are numerous. These include experience gained by individuals in performing routine tasks, improvement in the functioning of organizations (eg, plant management, logistics, marketing), and economies of scale (Cantley and Sahal, 1980). The causal mechanisms are well established, but learning is not the only means of reducing costs. Other factors that are external to learning by doing, such as improvements in upstream technologies, can also lower costs and are correlated with growing experience - thus the analyst must be careful when using learning curves that the mechanisms of learning apply to the situation at hand. At minimum, it appears that learning by doing requires continuous experience, not merely the accumulation of output regardless of its time path. Unit costs of the Lockheed L-1011 "Tristar" aircraft rose in the late 1970s when production resumed after a drastic reduction that included large-scale layoffs at production facilities. Experience gained during the early 1970 s was lost with the staff turnover; as a result, the planes built in the early 1980 s were in real terms more expensive than those built in the early 1970s (Argote and Epple, 1990).

Learning rates in manufacturing, including production of energy-related technologies, mainly vary from 10 to $30 \%$. In some cases, typically at the early stages of commercialization of a technology, learning rates approaching 50\% have been observed (Argote and Epple, 1990; Christiansson, 1995). A typical learning curve, shown in Fig. 2 for gas turbines used in electricity generation, consists of two segments. The first segment corresponds with the innovation stage - from the invention (adapted from jet aircraft engines) in the 1950s to the middle 1960s when the first gas turbine demonstration projects had been built and gas turbines entered niche markets. During this stage, cost reductions were rapid (some 20\% per doubling of the small installed capacity of demonstration projects); gas turbines were a truly radical technology - extremely expensive, but promising if substantial investments were made. The second segment, from the middle 1960s until 1980, is marked by smaller cost reductions for each doubling of experience, characteristic of expanding niche markets and early commercialization. Learning rates were approximately $10 \%$. During that period the technology was costlier than 


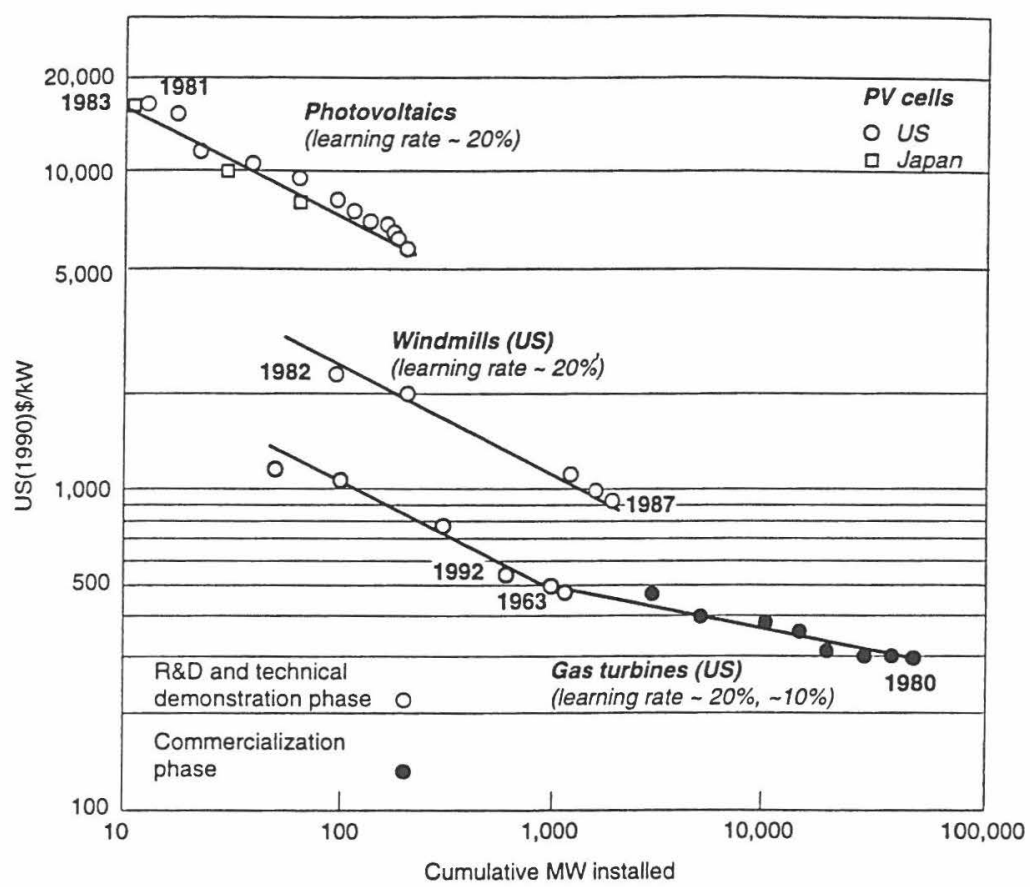

Fig. 3. Learning curves for several electricity generation technologies. Shown are gas turbines, which are an "incremental" technology on the cusp of widespread application (Fig. 2) and two higher cost technologies: photovoltaics and advanced windmills. These two more costly technologies are "radical" in that they are competitive only in special niche markets and thus market share is low, but both hold promise for lower costs with additional investments. Learning rates for all three technologies in their pre-commercial stage are comparable ( $\sim 20 \%$ per doubling of capacity).

Sources: see Fig. 2, and Christiansson (1995).

mature technology alternatives but became increasingly competitive through continued improvements that were sustained by substantial investments. Overall, the cost per unit of capacity declined by a factor of 4 as cumulative experience rose three orders of magnitude. Since 1980 gas turbines have been an incremental technology - increasingly applied in commercial markets as one component of the electricity generation system. Today, gas turbines are the preferred technology for most electricity generation applications and are in the midst of pervasive diffusion. Our estimate is that the total investments - R\&D and commercial sales for niche market applications - approached USS5 billion before the new technology became economically competitive with alternative electricity generation technologies beyond special niche markets. However, the exact cost of applied R\&D is difficult to estimate because statistics on such spending by private firms is typically not publicly available. Moreover, this figure does not include any of the original public and private investments into aircraft jet engines before their first derivatives were adapted for electricity generation.
Fig. 3 contrasts the learning curve of the gas turbines with two new renewable electricity generation technologies - wind and photovoltaics. Both technologies display rapid learning that began at high cost; already both can be competitive under special conditions. Wind power, for example, is profitable at sites with steady strong breezes, though often only with subsidies. Both are examples of radical technologies that are competing within an existing, mature technological system (i.e., electricity production and distribution). For producers of photovoltaics in both Japan and the United States, costs fell by over $20 \%$ with each doubling of capacity - a learning rate similar to the early history of the gas turbine.

A single learning curve, as in Figs. 2 and 3, helps convey the cost improvements that result from the complex processes of learning by doing in the commercial marketplace. But such conventional learning curves are inadequate for modeling the relationship between investments in a technology and consequences such as lower costs and improved performance which affect the ability of technologies to compete for market share. Such learning curves include only investments that yield experience 
in the commercial marketplace; they omit precommercial research and development (R\&D) as well as non-commercial demonstration projects that lead to commercial demonstration projects in niche markets. Yet, together, research, development and demonstration (RD\&D) are vital to the improvement of performance and the lowering of costs in the early stages of technological development. For example, the cost of photovoltaics produced in Japan halved between 1973 and 1976, but none of this improvement is evident in Fig. 3 because it was prior to any installation of demonstration units and thus cumulative installed capacity was zero. Such RD\&D expenditures are a small factor in the cost improvements of technologies that are already advanced to the stage of commercial niche markets and are candidates for pervasive diffusion, such as gas turbines in 1980 . But in the earlier stages, RD\&D accounts for a larger share of performance improvements and cost reductions. Thus learning curves must be expanded from their standard formulation if they are to be of practical use in modeling technological change that results from the changing competitive position of technologies. Doing so requires accurate and comparable data on applied research and development, which are usually scarce.

One of the few reliable sources of product-specific RD\&D expenditures is Watanabe's analysis of the Japanese Ministry of International Trade and Industry (MITI) "sunshine" technology program to promote new energy technologies such as solar photovoltaics (Watanabe, 1995, and personal communication). His exceptionally comprehensive data include both public (MITI) and private RD\&D expenditures. Watanabe estimated the parameters for a model that traced the direct and indirect (feedback) relationships between MITI-initiated RD\&D spending, private RD\&D spending, production of photovoltaics, and changes in the unit cost of photovoltaics in Japan. In his model, public RD\&D spending and other incentives stimulated industry RD\&D and increased the stock of knowledge specific to photovoltaics, which led to performance and cost improvements. Lower costs stimulated demand for these improved products, which increased the size of commercial niche markets and led to learning effects and further cost reductions. Larger commercial markets yielded production increases and additional stimulus for industrial RD\&D. In his terms, RD\&D lubricated a "spin cycle". (He excluded inter-industry and cross-national R\&D spillover effects, as well as those from purchases of equipment. ${ }^{3}$ Such effects flow into and out of firms that are investigating particular photovoltaic technologies and

\footnotetext{
"On "spillover" effects see Mansfield (1985): on the impact of equipment purchases see Organisation for Economic Cooperation and Deielopment (1996)
}

increase the stock of relevant knowledge, but they are notoriously difficult to quantify. ${ }^{4}$ ).

Parameters from Watanabe's plausible model can be used to plot a more comprehensive form of the "learning curve", shown in Fig. 4. The independent variable is cumulative investments, which includes RD\&D as well as commercial consumer purchases. Over the period 1973 to 1995 a total of 206 billion Yen (approximately US\$2.5 billion in 1995 prices and exchange rates) were spent on photovoltaics in Japan. 78\% (162 billion Yen) of that amount were actual investments in commercial photovoltaic capacity, and 22\% (44 billion Yen) was spent on RD\&D proper. The figure confirms that once a technology reaches the niche market stage that investments in hardware (ie, installed capacity) dominate, but that RD\&D is significant contributor to lower costs, especially in the early stages. Moreover, such investments and RD\&D cannot be treated as separate, independent sources of technological improvement. Only when combined does a curve that is characteristic of a learning curve materialize. Our understanding of the learning process is that it involves the interaction of both suppliers and users of technology.

This new "learning curve" has two important features. First, it is entirely economic and thus can be used in models that compute economic relationships between resource spending and changing prices of technologies. Such relationships are crucial for technological modeling because it is the anticipation of lower costs that leads to investments in immature technologies. In turn, those costs partially determine which technologies are selected for application, with environmental consequences. This chain of relationships - from investments to learning to cost reductions to market application to environmental consequences - is not perfectly known ex ante. Thus models which use of learning as a driving force of technological change must incorporate uncertainty, which we consider further below. ${ }^{5}$ Second, the curve is conceptually coherent because it includes both of the major sources of technological improvement - RD\&D and commercial purchases. This approach thus also addresses one of the critiques of conventional learning curves - they do not include RD\&D inputs. Similar curves can be calculated for other technologies, industries and countries, pending the availability of data.

\footnotetext{
${ }^{4}$ An analysis of inter-sectoral relationships of R\&D expenditures for the US and how these could be affected by climate policies (leading out to "crowding out" phenomena) is reported in Goulder and Schneider (1996) and Schneider and Goulder (1997).

${ }^{5}$ Postulating a relationship does not mean that the parameters of that relationship are known ex ante. Uncertainty therefore persists vis. the eventual outcome (level of improvement in cost and performance) and the level of investment (in R\&D and niche markets) needed to achieve a particular outcome.
} 


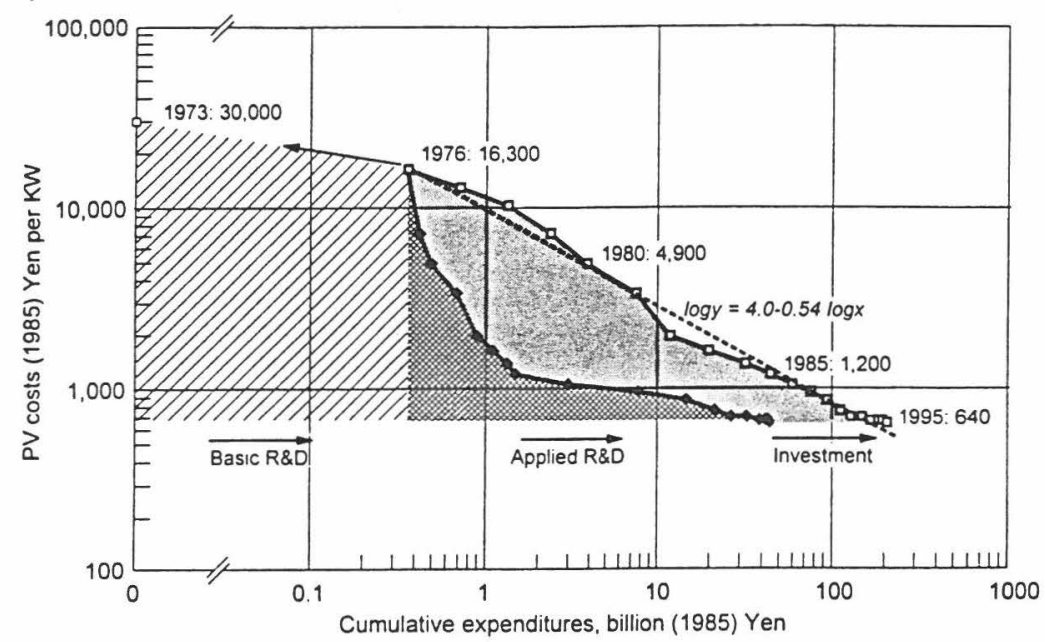

Fig. 4. Modified learning curve for photovoltaic technologies. The curve shows decline in costs as a function of cumulative investments including not only cumulative installations from demonstration projects and commercial niche markets but also R\&D investments. Conventional learning curves include only commercial installations and ignore other investments. At the early stages, when physical installations are few, R\&D is relatively important. The declining costs of photovoltaics correlate well with aggregate RD\& $D$ investments ( $R \& D$ as well as pre-and commercial demonstration projects) and are comparable with a classic learning curve pattern with $54 \%$ reduction in costs for each doubling of cumulative investment. This formulation allows a single, simple learning curve to be used to model cost reductions from the innovation stage as well as later commercial stages. (Note that these curves are not directly comparable with Fig. 3 because the independent variables and the currency units differ.) For more detail on the methodology used to produce this modified learning curve see Grübler and Gritsevskii (1998); data from Watanabe (1995, personal communication).

\subsection{Technology dinamics: market competition and diffusion}

Learning curves help illuminate the dramatic reduction in costs evident especially in the early stages of a technology - innovation, niche market commercialization, and the initial diffusion into widespread application. Learning curves help to identify technologies that might become competitive with adequate investment. But the tool is less powerful as the learning rate slows and a technology enters wider market application. In those situations, often many technologies compete and it is conceptually and empirically difficult to develop complete and robust learning curve models that include all technologies and processes that determine the outcome of dynamic competition between technologies in the marketplace. In the ideal world the modeler would estimate the cost and potential of all technologies and then determine the outcome according to cost differences. Empirically and conceptually that world does not exist (yet). Thus a multitude of techniques is needed.

In addition to learning curves, another approach is to identify general patterns by which technologies diffuse through competitive markets. Such patterns are often evident when plotting the fraction $(F)$ of a useful product or service, such as electricity or mobility, supplied by each major competing technology. The typical result is an S-shaped curve, which is often termed a logistic substitution or diffusion curve. At the earliest stage of commercialization, growth in a technology's market share is slow as the technology is applied only in specialized niche markets and costs are high. Growth accelerates as early commercial investments lead to compounding cost reductions and standard-setting, which leads to imitation and adoption in a wider array of settings. As the potential market is saturated and a product matures, growth in market share declines to zero. With the arrival of better competitors, the market share of the senescent technology declines. Such S-shaped curves are characteristic of many social and biological processes where the rate of diffusion or substitution depends on the probability of encounter between a supplier and a receptive host. Other studies of diffusion have applied these curves - pioneered by Lotka (1924) and Volterra (1927) - to the spread of infrastructures and technologies, as well as the diffusion of epidemics, ideas and forms of social organization (Hägerstrand, 1967; Fisher and Pry, 1971; Marchetti and Nakićenovic, 1979; Marchetti, 1980; Grübler, 1990; Astakhov et al, 1990; Buttner and Grübler, 1995; Nakicenović, 1990; United States Department of Commerce, 1975).

Perhaps the most famous case of technological substitution is motor cars for horses. In this simple case, one technological artifact, the passenger car, replaced 


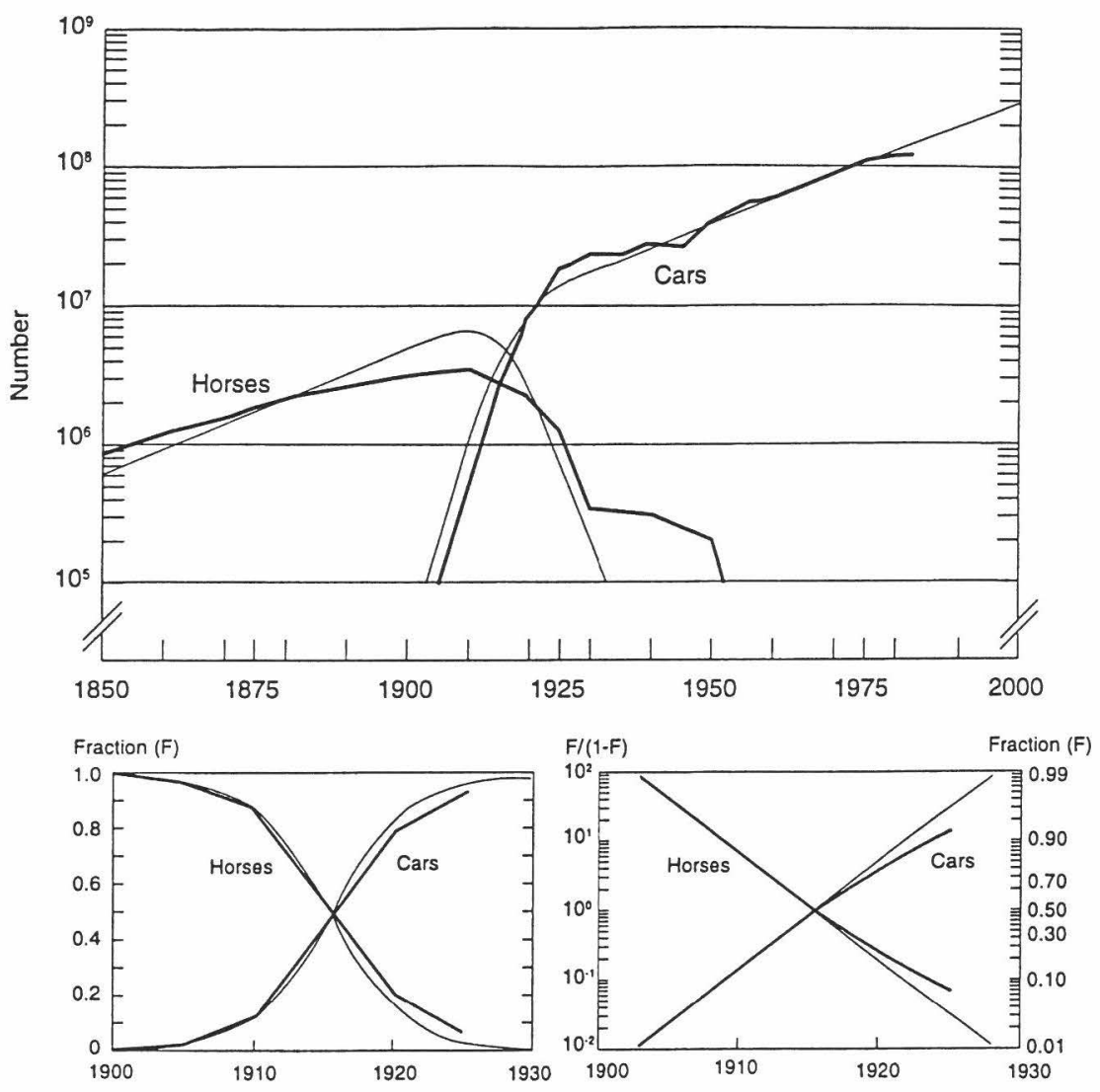

Fig. 5. A simple case of technological substitution. With a time constant ( $\Delta t$ ) of 12 yr. motor cars replaced horse-drawn carriages for transportation in the United States. The top panel shows this replacement in terms of number of units on the road. The data can be transformed into a format that highlights technological diffusion and substitution processes. That is shown in the bottom left panel, where the fraction $(F)$ of the total number of road vehicles (horse carriages + automobiles) accounted for by each technology is shown. In this simple substitution process, two symmetrical S-shaped curves are the result. The smooth lines are a fit from a logistic model (see Grübler, 1990). The bottom right panel transforms the fraction data into a format that converts S-shaped diffusion processes into straight lines by showing the logarithm of $(F /(1-F))$, ie, the ratio of the market share achieved by a technology over that remaining to be achieved.

Suturce: Nakicenovic (1986).

another individual transport technology: the riding horse and the carriage. Looking at the absolute numbers of draft animals and cars in the USA (Fig. 5), we see that the millions of horses and mules used for transport practically disappeared from the roads within fewer than three decades. Interestingly, growth in transport services - approximated by the growth in the sum of vehicles on the road (horse carriages + cars) - rose smoothly and continuously, largely unaffected by the fierce competition. The time constant $(\Delta t)$, which measures the time required for a new technology to grow from 10 to $90 \%$ eventual market share, was only $12 \mathrm{yr}$, fast enough to traumatize the displaced oat growers, coachmen, blacksmiths and (fatally) the horses. Similar time constants are observed in other cases of single transportation technologies competing in a common infrastructure. For example, the diffusion of modern low-emissions vehicles with catalytic converters also occurred with the time constant of $12 \mathrm{yr}$ in the USA (Grübler, 1996; Nakićenović, 1986). Decadelong time constants also governed the replacement of railway rolling stock and substitution of steam by dieselelectric locomotives (Grübler, 1990).

Typically many technologies compete, not just two. When competitors arrive in the market at different moments in time, the result is a sequence of S-shaped logistic curves. For example, in steel manufacturing (Fig. 6) as many as four technologies have competed simultaneously, with varied time constants. The simple direct 


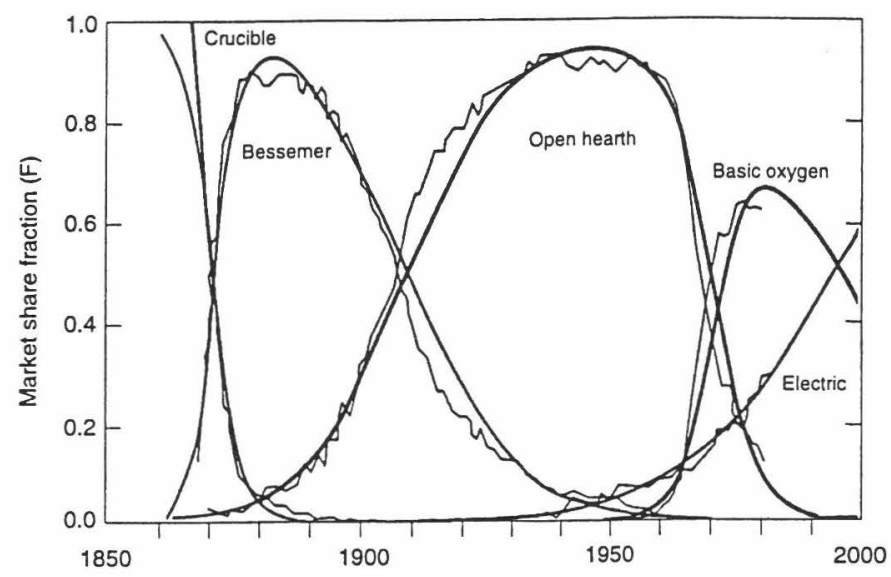

Fig. 6. Competition among multiple technologies. Figure shows the share of steel production in the United States by five different methods, 1850 to the present. and curves (estimated from a logistic model) for the near future. In the 1940s and 1950s four different technologies competed simultaneously to supply the steel product.

Source: Nakicenović (1990).

replacement of crucible processes took less than two decades. Its much superior replacement, the Bessemer process, enabled for the first time mass production of high quality steel at low costs. Nearly seven decades were needed for the diffusion of electric arc steel in the USA, which was accompanied by other long-term changes in the steel industry, such as increased use of (recycled) scrap in steel manufacture, the emergence of "mini mills" and made-to-order small batch production. That longer replacement process entailed far-reaching changes in industrial structure, shifts to flatter economies of scale, and availability of steel scrap as raw material instead of iron ore. $^{6}$

The S-shaped curves are useful for analyzing two similar but distinct processes - diffusion and substitution. The former refers to the spread of a technology into wholly new markets, often to provide services that previously did not exist. Substitution is the replacement of an existing technology with a new one, such as Bessemer for crucible steel production or motorized cars for horsedrawn carriages. However, a firm distinction between the two processes is often difficult because both affect the supply of and demand for a service. Often substitution of an old technology by a new one yields lower prices and better performance; more efficient supply of the service induces greater demand. The expansion of automobile

"Analysis of economic determinants of different diffusion rates found that ceteris paribus diffusion rates are higher (faster) for technologies with higher relative economic advantage (performance, costs) and lower investment requirements. See the classic studies of Mansfield (1961, $1968)$ and Mansfied et al (1977). travel in the United States, for example, is often analyzed as two overlapping processes. The first entailed the rapid substitution for horse carriages shown in Fig. 5, and second was the longer diffusion process during which automobiles co-evolved with the growing road network and redefined American mobility. Similarly, the growth of railroads in the United States beginning in the 19th century is often cited as a case of pure diffusion - the new technology (railroad) and services it provided were novel. However, over a shorter period, the railroads also largely substituted a feeble competitor - stagecoaches - out of the business of inter-city transportation.

The competitive status of a technology is indicated not only by changes in its market share but also by costs. Fig. 7 shows proxies for costs for the three main transport modes that have competed this century to supply US transportation services. As expected, costs declined most rapidly at the earliest stages of technological development when market diffusion was most rapid - for railways in the 1870 s (but data are scattered and time series are not available), roads for automobiles in the 1900s and 1910s, and air travel in the 1930s and 1940s. (For more on transport infrastructures, see Fig. 10 and discussion below.) Fig. 8 illustrates the relationship in more detail for one technology: the automobile and its surfaced road infrastructure. The sales value of new automobiles, which fell sharply as the automobile was commercialized, in tandem with the early growth of the necessary surfaced road infrastructure. Ideally we would illustrate these principles with data on automobile operating costs and levels of mobility, but neither was reliably measured before the 1950s. 


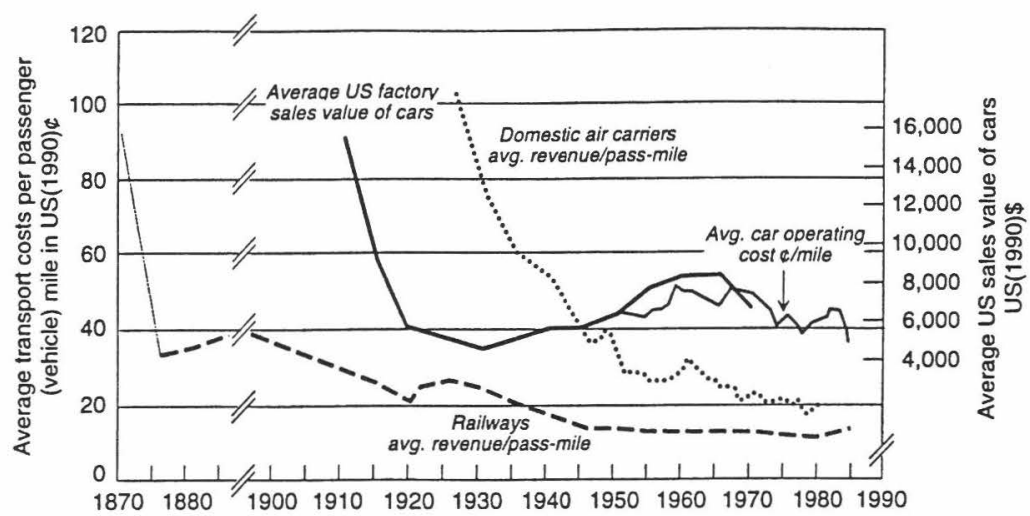

Fig. 7. The cost of passenger transport in the United States has declined as the systems matured. As with individual technologies, the cost of transport systems has declined most rapidly at the early stages. Nonetheless, continued cost reductions have been possible even in "mature" systems (eg. railroads) under severe competition from new, superior technologies (eg. air transport). (Operating costs, which are a better indicator of the economic attractiveness of the automobile, are available only since the 1950s; thus new car costs are used prior. Similarly, rail and air cost data would be better indicators but are not available in comparable formats; thus revenue statistics are used as a good proxy.)

Sinurce: Grübler (1990).

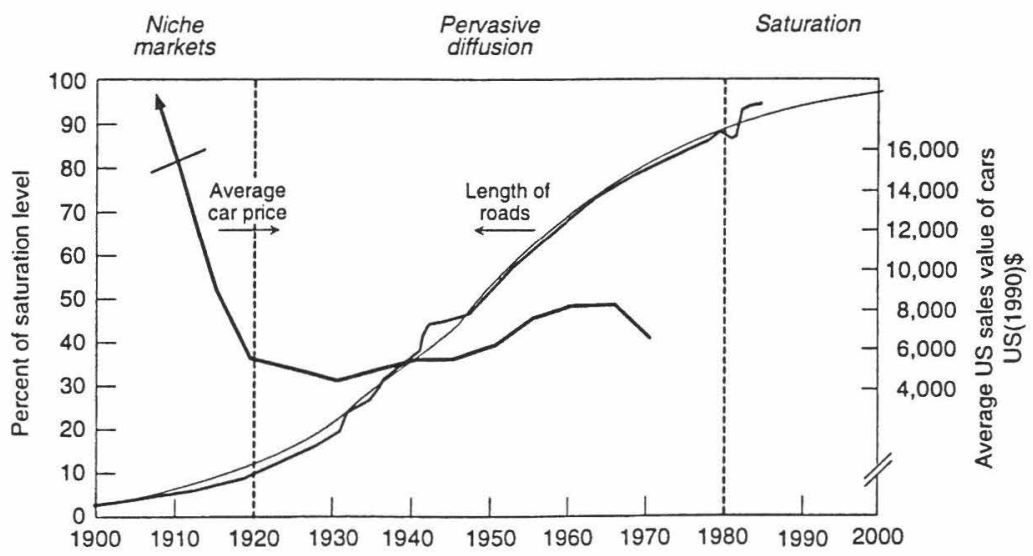

Fig. 8. The co-erolution of automobile costs and the road network in the United States. Automobile and production methods improved, which lowered the cost of new automobiles. At the same time the surfaced road network grew. These cross-enhancing developments occurred during the niche marhet commercialization and the early stages of pervasive diffusion (1905 to 1930). As automobiles became entrenched and served additional functions (eg. icons of stutus): product life cycles shortened, and costs rose. Compared with niche market days, however, average sales costs have been remarkably stable at approximately USS7000 to US\$8000 (1990 dollars, adjusted with IMF GDP deflators).

Source: Grübler (1990).

Although a sharp drop in costs marks the onset of pervasive diffusion, costs are not static once a technology is in widespread use. For example, the length of the railway network reached $80 \%$ of its saturation by 1910 nonetheless, real costs per passenger-mile have since declined by half. Further improvements are still possible - for example, traffic management systems are improving rail speeds and load factors, thus sustaining competition with roads and airways for passengers and freight. A dying competitor does not exit without a fight - a phenomenon also called the "sailing ship effect" (Ward, 1967). When steam ships became competitive in the 1850s for ocean-going freight and passengers, sail-powered boats improved significantly. Indeed, the "golden age" of Clipper sailing ships emerged only once steam ships had appeared as competitors; Montroll (1978) has estimated 
from historical data that this effect may have delayed the extinction of sail ships by one decade. Although sailing ships were slower and less competitive for passenger traffic they did preserve a niche in hauling less time-sensitive freight, including, ironically, coal for steamers.

Despite variable time constants and substitution processes, the basic patterns of technological substitution and diffusion are largely invariant across a large and diverse set of historical examples. Theory suggests that the characteristic time constants of technology substitution and diffusion vary depending on characteristics intrinsic to new technologies (such as their costs, performance, social acceptability) as well as a function of more general "systemic" characteristics of technology. For instance, ceteris paribus, diffusion can proceed faster when replacing an artifact that previously provided a similar function; technologies that provide an entirely new service diffuse more slowly. The replacement of black-andwhite TV sets by color ones, for example, proceeded in all markets much faster than the initial diffusion of blackand-white TVs. ${ }^{\text {? }}$

The diffusion model can be extended from competition in a single market to separate or only loosely linked markets. That phenomenon is common in technological analysis because technologies are developed and tested in small, core markets from which they diffuse globally. An immature new technology is more costly and requires greater investments to be competitive in its first market; the diffusion time is thus longer when compared with the periphery. However, the longer period of establishment allows the technology to have a larger effect on setting standards that bar competitors and thus the penetration level is higher in core markets. Because much technological knowledge is a free good peripheral regions can "catch up" rapidly to the core, as the technologies have been tried out already in core markets, and initial high costs have already declined through R\&D efforts and learning effects.

Historical analysis confirms that the periphery generally reaches lower adoption levels when compared with core markets (E Schmidt, cited in Marchetti, 1983; Grübler, 1991). For example, the automobile diffused into widespread passenger service first in the United States with a time constant $(\Delta t)$ of $60 \mathrm{yr}$. At its 1960 s peak in this core market automobiles supplied over $90 \%$ of all motorized passenger kilometers. In contrast, the diffusion rate was more rapid in Europe ( $\Delta t$ about $30 \mathrm{yr}$ ), but today European automobile travel is saturating at about $70 \%$ of total passenger kilometers. In countries starting motorization even later, the diffusion rate for

- Characteristic diffusion rates of black-and-white TV sets are $30 \mathrm{yr}$ in OECD countries, whereas the replacement of black-and-white by color TV sets took typically only about half that time. See Steward (1982). automobiles has been even more rapid - about two decades in Japan and in Latin America, for example - but the saturation level will probably also be lower. In the peripheral regions, automobile shares are lower in part because the next generation of transport technologies - high speed trains and aircraft - are already diffusing and substituting rapidly. In core regions, entrenchment or "lock in" of dominant technologies can also limit competition and the development of new alternatives. ${ }^{8}$ Hence, market shares are higher and saturation takes longer.

Viewed together, early and late markets exhibit a strong focusing of diffusion - as the technology reaches saturation the fraction $(F)$ of saturation level narrows between early and late markets. This phenomenon is illustrated in Fig. 9 for the major transport infrastructures in industrialized countries during recent centuries. Ultimate saturation occurs in all markets over a relatively short common time period. Such synchronicity may be evidence and cause of world economic cycles (Grübler, 1991).

\subsection{Infrastructures and technological clusters}

Learning curves help modelers estimate performance and cost improvements in the early stages of a technology, and the diffusion model helps model the dynamics that result from selection of technologies in competitive markets. Individual and firm-level decisions that result in the selection of technologies are often so numerous and complicated that they can not be modeled individually. Learning curves and substitution/diffusion models allow simplified, but powerful and conceptually coherent, means of modeling technological changes and dynamics. But by themselves neither technique is complete. Neither fully explains which technologies attract investments and survive to the market; nor does either tool internally determine the rates of change, such as $\Delta t$, and extent of diffusion that prevails in the marketplace.

The fuller picture is partially completed by analyzing clusters of related technologies, not only the individual components. Individual technologies cause externalities; as technologies grow synergistically, the network effects increasingly bind the fates of all technologies in the cluster. At the center of these clusters are "infrastructures" - technologies that serve mainly the purpose of supplying externalities. The most obvious examples are energy, transport, and communication infrastructures, without which numerous end-use technologies could not function. Since the cluster partially determines the selection of its technological components, it also strongly influences environmental impacts.

\footnotetext{
${ }^{8}$ For a more detailed discussion and model of technological "lockin" see Arthur (1983, 1989) and David (1985).
} 


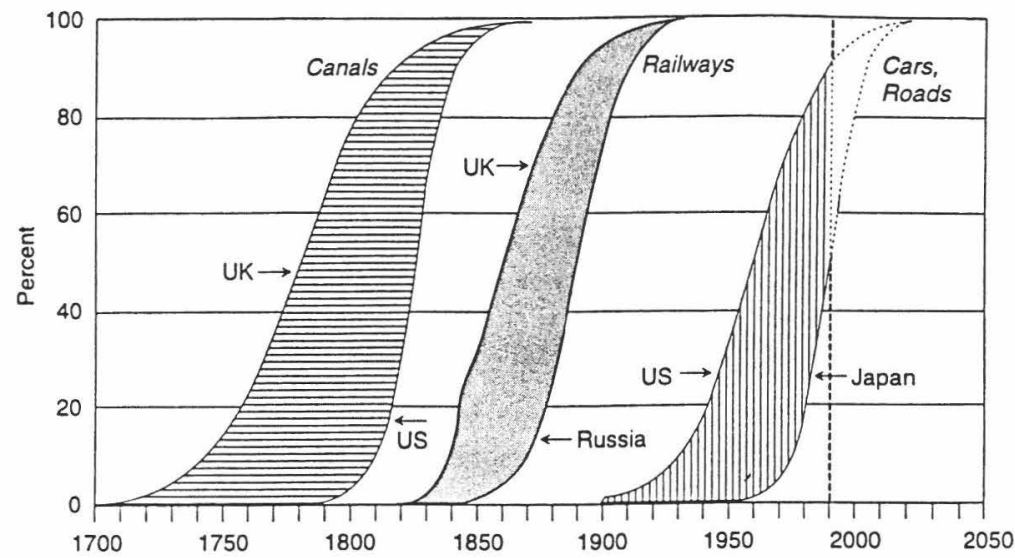

Fig. 9. Focusing of diffusion between leading and laggard markets, industrialized countries. Technologies and infrastructures have co-evolved across countries in industrial society. Three eras are evident, each defined by its principal transport infrastructure - canals, railways. and roads (cars). Those infrastructures also correspond with three different principal energy sources - wood, coal and oil, respectively. The initial stages of diffusion of each transport infrastructure are marked by high diversity in starting dates and diffusion speeds, which focus as the technology cluster matures. The countries indicated are those industrial nations for which diffusion was earliest (and slowest) and latest (and fastest). The $Y$-axis shows the respective size of transport infrastructures as a fraction of their historical saturation levels (forecasted in the case of cars). The next technology cluster might be defined by aircraft and trains that operate at similar speeds, electricity and natural gas.

Source: Grübler and Nakičnovic (1991).

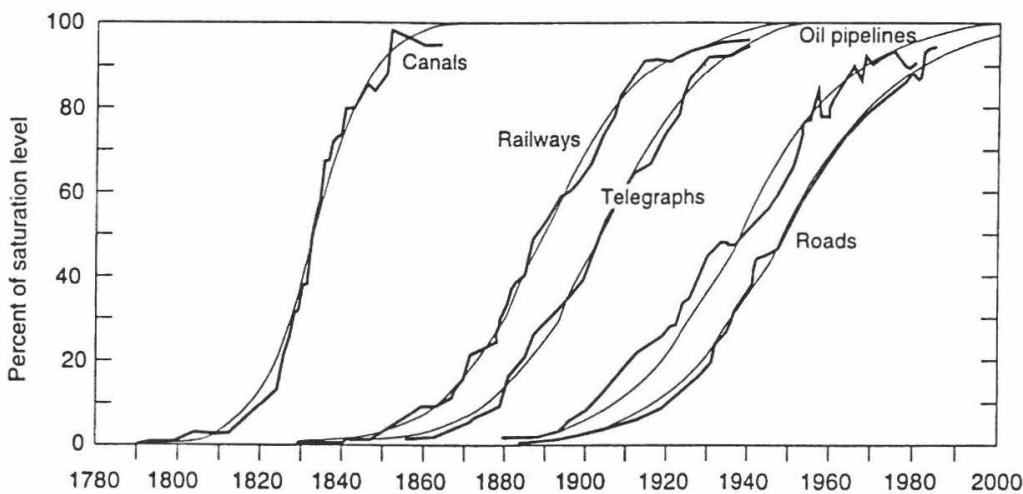

Fig. 10. The evolution of infrastructures in the United States. The figure shows the length of the three major transportation infrastructures (canals, railways and hard surficed roads) as a fraction of their total saturation levels. The total length grew approximately ten-fold for each new infrastructure. At their peak in 1851 canals extended over $6500 \mathrm{~km}$. Railroads peaked at $490,000 \mathrm{~km}$ in 1929 . Growth in the road network has slowed considerably, and with a logistic model we estimate that it will soon saturate at approximately 6 million kilometers. Analysis in terms of total saturation is the same as application of the fraction concept $(F)$ introduced in Fig. 5. Also evident in the figure is the co-evolution of compatible infrastructures: railways and telegraphs: roads and oil pipelines.

Source: Grübler and Nakičenovič (1991).

The importance of infrastructures and of networks for long-term technological evolution and economic growth is a well covered field (Schumpeter, 1934; Isard, 1942; Hughes, 1983; Anderson et al, 1984; Teubal et al, 1996).
Infrastructures, like other technologies, can be analyzed with the diffusion model. Fig. 10 shows the case of transportation infrastructures. Canals, rails and roads have each evolved along a similar S-shaped dynamic pattern. 
In the figure the size of individual networks has been normalized by the saturation level for each infrastructure; the values shown are the fraction $(F)$ of that level. In absolute values, surfaced roads were an order of magnitude longer than the rail network, which was one order of magnitude larger than the maximum length of the canal system. In time, the three infrastructures are spaced rhythmically apart by a half-century or so. The duration of growth $(\Delta t)$ has risen slightly with each new, longer infrastructure. Today, surface roads are saturating; aircraft infrastructures are growing rapidly, though comparable measures are not available: modern aircraft navigation, traffic control and "airways" are a different kind of infrastructure compared with railways and roads.

Infrastructures yield externalities - "network effects" - that allow compatible technologies and infrastructures to prosper while raising high barriers for products and processes that are incompatible. Components of these networks thus co-evolve. Such externalities are also often found between infrastructures. Fig. 10, for example, suggests that the railway and the telegraph evolved together - both used the same strips of land (rights of way). Synchronization is also evident in the evolution of the road network and the oil pipelines that deliver fuel to power cars and trucks. Such technological interdependence - or technology "clusters" - are responsible for the pervasive effects of technological change throughout the economy and society. For example, the emergence of pipelines and petrol retailing has reinforced the dominance of petroleum-fueled automobiles and made it increasingly difficult for incompatible electric vehicles to supply automobility at the turn of the century. Only with the redefinition of automobile performance by requiring lower specific vehicle emissions has electricity re-emerged as a possible automobile propulsion. Technological interdependence is also a source of considerable inertia in technological systems. In that respect, numerous technological systems are "locked in" to particular configurations which are inherently difficult to dislodge within a short period of time. The constrained evolution of technology clusters over time is also referred to in the literature as "path dependence". Models of induced innovation often describe technological change as a cumulative process and thus can explain the phenomenon of path dependency (Binswanger, 1978; Ruttan, 1996).

From a macro perspective, the network effects of infrastructures create technological clusters. Infrastructures lie at the center of technological clusters that define major eras in economic development - for example, the age of "railways" or the "automobile era". The diffusion of technologies shown earlier in Fig. 9 (for the industrialized countries) and in Fig. 10 (for the USA) are the infrastructures that define those eras - they are both indicators and causes of the network effects that create the cluster. ${ }^{9}$ Analysis at the level of individual countries and markets is important because it is crucial to examine the diffusion of technologies within the boundaries of their network effects, which typically coincide with the boundaries of coherent social system.

Three rather clear clusters can be distinguished, although the individual technologies entered the market at different dates and diffused with different time constants. The first cluster saturated around 1865, the second around 1930, and the third is saturating now. Due to the overlap of technologies between clusters, perhaps a fourth cluster of technologies has been already launched, but is not yet clearly perceivable due to the insignificant degree of diffusion achieved to date by its key constituent technologies. Looking back from the future, the new emerging cluster might be one day characterized by dematerialization, the dominance of natural gas and electricity infrastructures, and worldwide communications that are too cheap to meter.

Technology clusters partially determine the time constants $(\Delta t)$ that govern the diffusion processes. Fig. 11 shows the cumulative frequency distribution of $\Delta t$ for 265 diffusion processes in the USA, based on studies performed at IIASA (117 cases) and 148 other welldocumented examples from the literature (Grübler, 1991). The case studies include diffusion of energy, transport, manufacturing, agriculture, consumer durables, communication, and military technologies, as well as economic and social processes, such as literacy, reduction of infant mortality, and changes in job classes. The time constants of change range from very short-term processes of only a few years to processes that extend over two to three centuries. The mean value of the time constants is $41 \mathrm{yr}$, with a standard deviation of about equal size. Few diffusion processes extend more than one century and thus span more than one cluster. Half of the diffusion processes have $\Delta t$ of less than $30 \mathrm{yr}$; about three quarters have $\Delta t$ of less than $50 \mathrm{yr}$; and $93 \%$ of the sample exhibits $\Delta t$ of less than $100 \mathrm{yr}$. Analysis that distinguishes the types of technologies in the data sample suggests that the appropriate time constants for diffusion of infrastructures and of entire technology clusters span up to a century (Fig. 10), with the main period of growth extending between 5 to 6 decades. Most technologies diffuse within the time-period of a single cluster. Only a few

\footnotetext{
${ }^{9}$ Technology clustering and network effects are also referred to as technological interdependence in the literature. Technological interdependence can delay diffusion of new technologies that are either incompatible with existing network effects, or need considerable time to establish their own. The classic paper (and model) on this topic remains Frankel (1955). Recently, similar concepts have been included in form of a "technological inertia" variable in traditional macro-economic model formulations with exogenous technology to analyze its impact on climate policies and their timing (Ha-Duong et al, 1997), although application of the model is difficult since the phenomenon of "inertia" has not been crisply defined nor is it currently measured.
} 


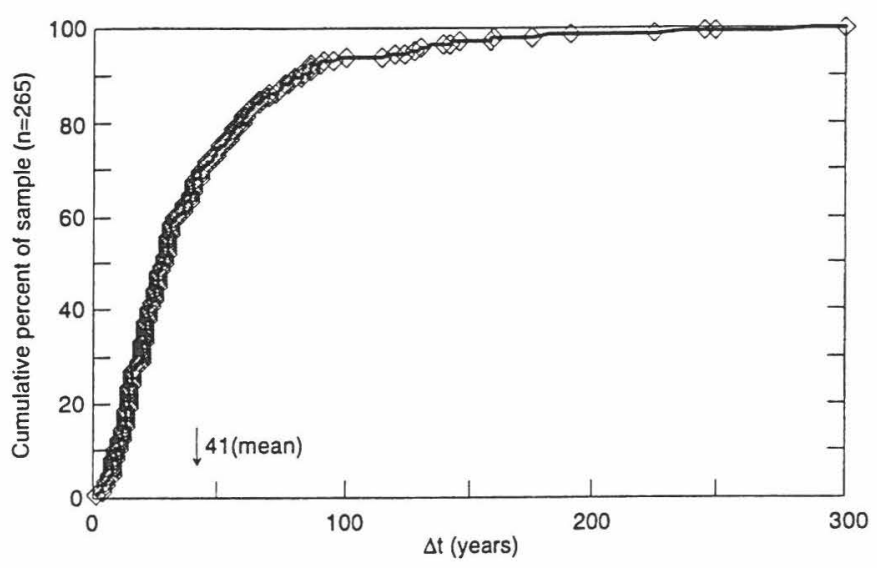

Fig. 11. The cumulative distribution of diffusion rates $(\Delta t)$ for 265 diffusion processes. The sample is the superset of diffusion processes documented in the literature and those analyzed at IIASA. The mean rate is $41 \mathrm{yr}$ and the standard deviation is $42 \mathrm{yr}$.

Source: Grübler (1990).

technologies can tunnel from one to another cluster such as some infrastructures.

In sum, technical change remains an extremely complicated process. The diffusion/substitution model can help simplify the modeling of that process and thus can aid in the projection of market shares and global change effects of specific technologies. It remains impossible to determine - from theory or statistical analysis of historical data - exactly what rates $(\Delta t)$ will prevail in particular circumstances. But both theory and history can help modelers by bounding a range of plausible rates, which Table 2 summarizes and illustrates. Those rates can be used for future projections; statistical methods and packages exist for estimating diffusion parameters for a varicty of models, from simple one-on-one competition to competition between multiple technologies (Grübler 't al, 1988: Marchetti and Nakićenović, 1979; Meyer, 1994).

In general, revolutionary changes score high on each of the factors summarized in Table 2 and thus are marked by long diffusion constants. Such changes can be robustly identified only with hindsight of several decades, when the cluster, including its infrastructures, has substantially diffused into use and the interdependencies are evident in practice. A future hydrogen-powered economy will require not only new end use technologies (eg, fuel cells) but also infrastructures (eg, hydrogen pipelines) and interdependent technologies (eg, upstream hydrogen production methods). Individually some of those elements may be able to diffuse rapidly -for example, today there is substantial production of hydrogen for use in refineries - but the system as a whole can emerge only at the pace of the necessary infrastructure, ie over a time span of several decades. Indeed, the historical record shows that the largest technological systems diffuse with long time constants (6 to 8 decades).

\section{Implications for global change}

The typology and basic observations on patterns of technological change evident in the historical record allow at least three improvements to the way that analysts model technological changes and their environmental impacts. One improvement is based on a longterm pattern that is directly evident in the historical record - the existence and pace of decarbonization. The other two concern modeling. At the micro level it is possible now to endogenize rigorously the process of technological change due to (uncertain) learning. At the macro level it is possible to employ modeling techniques that stylistically endogenize technological change, but only if conventional macroeconomic models are linked with models that allow resolution in the choice of particular technologies. None of these three improvements is fully reflected in the mainstream models and scenarios that are being used to analyze global change.

\subsection{The historical record: decarbonization}

The existence of technological clusters partially determines the selection of energy sources and thus environmental effects. When fuel wood and animal feed were the prime sources of energy, people traveled mainly by foot (walking and horses) and boat (canals). During the age of coal, railways provided most mobility; today, in the age 
Table 2

Examples of Iiffusion processes

\begin{tabular}{|c|c|c|c|c|c|c|c|c|}
\hline Duration & $\begin{array}{l}\text { delta } T \\
\text { (yr) }\end{array}$ & Example & $\begin{array}{l}\text { Diffusion (D) } \\
\text { Substitution (S) }\end{array}$ & Reference & $\begin{array}{l}\text { Relative } \\
\text { advantage }\end{array}$ & Scale & $\begin{array}{l}\text { Infrastructure } \\
\text { needs }\end{array}$ & $\begin{array}{l}\text { Technical } \\
\text { interdependence }\end{array}$ \\
\hline \multirow{8}{*}{$\begin{array}{l}\text { Long } \\
>40 \mathrm{yr}\end{array}$} & 110 & Coal vs. traditional energy, World & $\mathrm{s}$ & Nakićenović (1984) & ++ & +++ & +++ & +++ \\
\hline & 80 & Coall vs. traditional energy, USA & $\mathrm{s}$ & Nakićenović (1984) & ++ & +++ & $+t+$ & $++t$ \\
\hline & 60 & Growth of railwalys, World & $\mathrm{D}$ & Grübler (1990) & +++ & +++ & +++ & +++ \\
\hline & 47 & Growth of railwalys, France & $\mathrm{D}$ & Grübler (1990) & +++ & ++ & +++ & +++ \\
\hline & 55 & Stcam vs. sailships, World & $\mathrm{s}$ & Grübler (1991) & +++ & +++ & ++ & + \\
\hline & 70 & Open-hearth steelmaking. World & $\mathrm{s}$ & Nakićcnović (1990) & ++ & +++ & + & + \\
\hline & 55 & Open-hearth steelmaking, USA & $\mathrm{s}$ & Nakičenović (1990) & ++ & ++ & + & + \\
\hline & 44 & Electrification of homes, USA & $\mathrm{D}$ & US DOC (1975) & +++ & +++ & ++ & ++ \\
\hline \multirow{7}{*}{$\begin{array}{l}\text { Medium } \\
20-40 \mathrm{yr}\end{array}$} & 25 & $\%$ houscholds with radio, USA & D & US DOC (1975) & +++ & ++ & + & ++ \\
\hline & 26 & Air vs. rail in intercity travel, USA & $\mathrm{s}$ & Fisher and Pry (1971) & ++ & ++ & ++ & ++ \\
\hline & 28 & Mechanization in coal mining, USSR & $\mathrm{s}$ & Astakhov et al (1990) & ++ & + & + & ++ \\
\hline & 25 & Basic oxygen steel furnace, World & $\mathrm{s}$ & Nakićenović (1990) & + & $++t$ & + & + \\
\hline & 20 & Basic oxygen steel furnace, UK, USA & $\mathrm{s}$ & Nakićnović (1990) & + & ++ & + & + \\
\hline & 27 & Railway track electrification, USSR & D & Grübler (1991) & + & ++ & ++ & ++ \\
\hline & 26 & Chemical preservation of railway ties USA & $\mathrm{s}$ & Grübler (1991) & ++ & ++ & + & + \\
\hline \multirow{10}{*}{$\begin{array}{l}\text { Fast } \\
<20 \mathrm{yr}\end{array}$} & 18 & Car air conditioners, USA & $\mathrm{D}$ & Nakićenović (1986) & + & ++ & + & + \\
\hline & 19 & Air conditioners in homes, Japan & $\mathrm{D}$ & Buttnerr and Grubler (1995) & + & ++ & + & + \\
\hline & 16 & Automobiles vs cariages, UK & $\mathrm{s}$ & Grübler (1990) & +++ & + & ++ & ++ \\
\hline & 15 & Cars vs. horses, France & $\mathrm{s}$ & Grübler (1990) & +++ & + & ++ & ++ \\
\hline & 12 & Cars vs horses, USA & $\mathrm{s}$ & Nakićenović (1986) & +++ & + & ++ & ++ \\
\hline & 16 & $\begin{array}{l}\text { Cars vs horses, UK \& France } \\
\text { Diesel/electric vs. steam }\end{array}$ & $\mathrm{s}$ & Grübler (1990) & ++ & + & ++ & ++ \\
\hline & 12 & Locomotives, US, USSR, UK & S & Grübler $\left(1 s^{\prime} ; 0\right)$ & + & + & + & + \\
\hline & 15 & Transistors vs. vacuum tubes in radios, USA & $\mathrm{s}$ & Steward (1982) & + & + & + & ++ \\
\hline & 15 & Black and white vs. color TV. USA & s & Steward (1982) & + & ++ & + & + \\
\hline & 9 & Washing detergent vs. soap, USA & $\mathrm{s}$ & Fisher and Pry (1971) & + & + & + & + \\
\hline
\end{tabular}

Note: Stylized summary of diffusion rates and their determinants. The rate of diffusion $(\Delta t)$ of technologies is determined by many factors. Four major ones are summarized in the table that, other thing being equal, have the following effects. (a) Relative advantage, comprising a variety of dimensions including engineering (eg, performance, productivity), economic (eg, relative costs, profitability), and social (eg, ease of adoption and use). The higher the relative advantage of a new technology compared to existing ones, the higher (faster) will ceteris paribus be its diffusion rate. (b) "Size," comprising a variety of dimensions like geographical spread (eg local vs. global), market size and adoption in specialized applications (eg, process technologies in specialized industries) vs. pervasive adoption (eg, in every houschold). Ceteris paribus, larger size implies longer (slower) diffusion rates. (c) Infrastructure needs (network externalities), which imply ceteris paribus longer (slower) diffusion rates. Although frequently an important overlap exists between infrastructures and large technical systems, not all large-scale technologies require new infrastructures. For instance, nuclear power was able to diffuse relatively rapidly by profiting from an electricity transport and distribution infrastructure largely already in place. (d) Interdependence with other technologies. Ceteris paribus, the higher technological interdependence, the slower individual technologies diffuse. The latter two factors that are often interrelated are frequently termed "network effects." For each illustrative example of technological diffusion or substitution, the authors have qualitatively scored each of above influencing factors ranging from low $(+)$, medium $(++)$, to high $(+++)$. Ceteris paribus, more " + " symbols lead to diffusion or substitution, the authors have qualitatively scored each of above influencing factors ranging from low $(+)$, medium $(++)$, to high $(+++)$. Ceteris paribus, more " + " symbols lead to
longer (slower) diffusion rate, but also indicate more pervasive impacts of technological change. Our approach and classification is highly stylized, as few of these concepts have been represented by comparable indicators for which data are available. For each illustration the table also indicates whether the process is predominantly diffusion (D) of the technology into a new service, or substitution (S) for an existing technology. However, in most cases firm classification is difficult (see text for explanation). Substitution processes are often more rapid than diffusion because they typically occur within a technological system that is compatible with both the old and new (substituting) technology. 

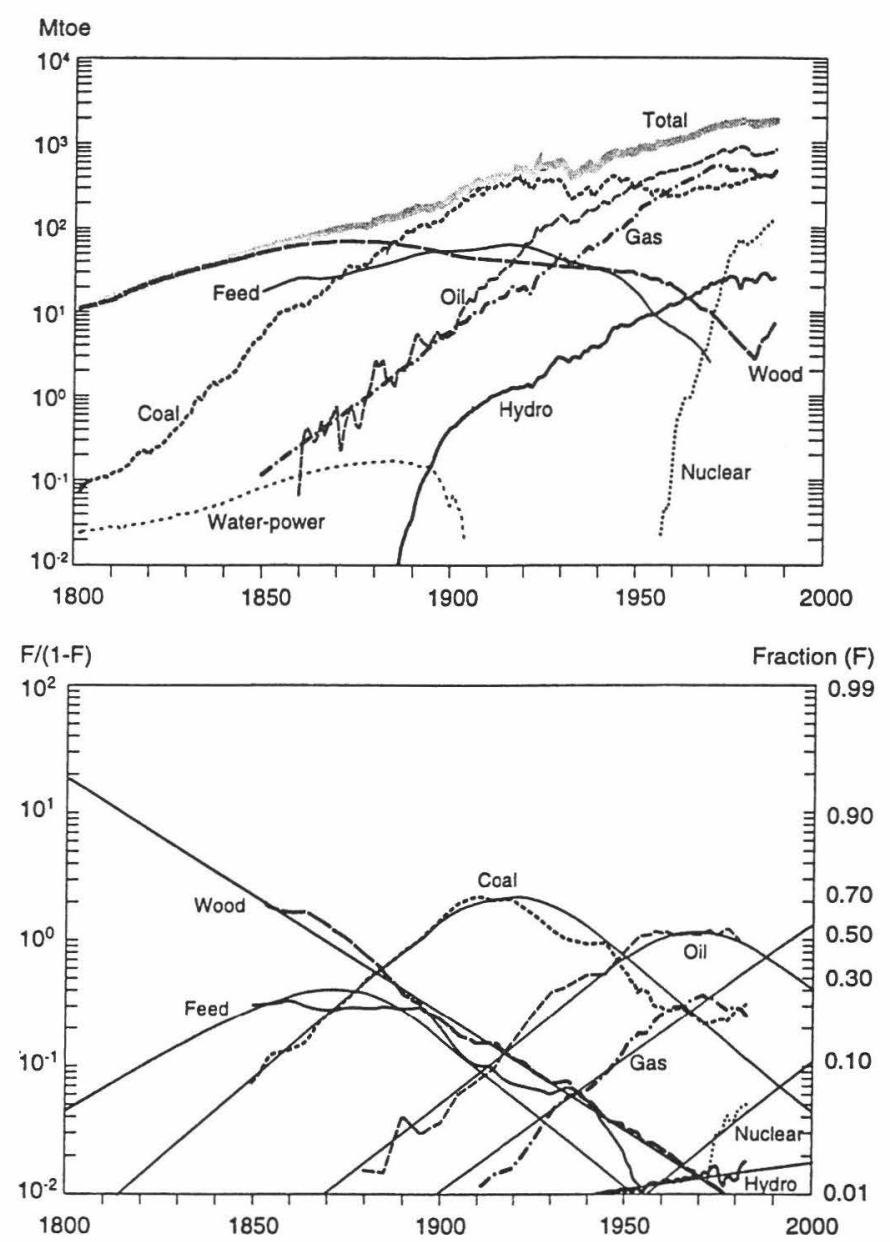

Fig. 12. Selection of fuels progressively lighter in carbon. Figure shows the primary energy supply in the United States in familiar units (million tons of oil equivalent. Mtoe). For each major fuel its fraction $(F)$ of total energy supply was calculated, and then transformed as in Fig. 5 so that logistic substitution processes appear as straight lines. The result, shown in the bottom figure, makes it easier for the human eye to identify those processes at work. US data are used because they are the most complete.

Sources: Nakićenović (1984) and Grübler and Nakičenović (1991).

of oil, automobiles, buses and aircraft provide unprecedented levels of individual mobility. When people and materials traveled by foot, most energy was consumed at the point of gathering; in contrast, today, most energy is itself transported. Increasingly, energy is converted into a readily usable form (eg electricity) prior to transportation. The share of final energy supplied by electricity is growing rapidly in most countries and worldwide, with no sign of saturation (Ausubel and Marchetti, 1996). The environmental problems of at-source energy gathering were localized, such as deforestation adjacent to roads and settlements. Today the reach is global, and part of environmental concern is focused on the transport of fuels themselves, such as oil spills and electromagnetic fields.

Fig. 12 shows the shares of total primary energy in the United States supplied by different fuels (top panel) and estimates for the consumption of major primary fuels worldwide (bottom panel). We use US energy data often in this survey and review paper because the statistically documented record is longest and thus technological dynamics most evident. As with the evolution of 


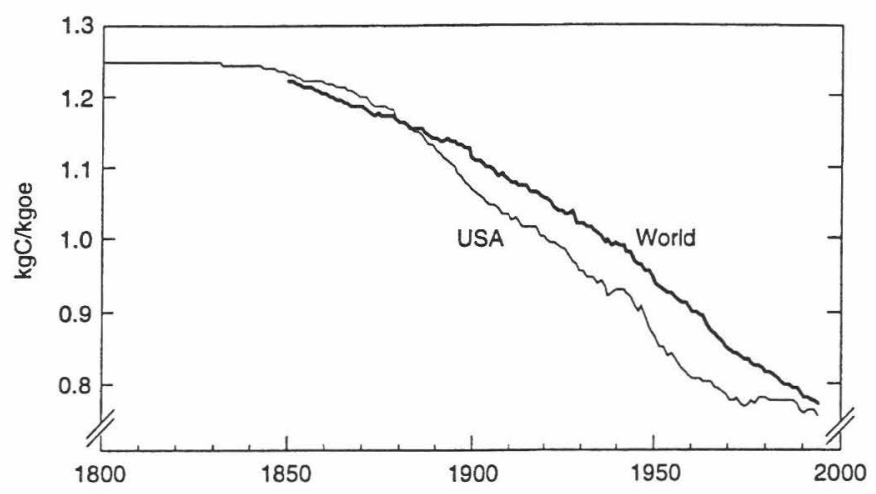

Fig. 13. Decarbonization of the energy supply. The ratio of carbon per unit of energy has steadily declined in the United States and the World. Data for this figure and Fig. 12 include estimates for fuel wood and feed (biomass) that were major energy sources until the middle/late 19 th century. We are mindful that their carbon intensity depends on the mode of production; for the purpose of calculating decarbonization we make the reasonable assumption that production of these fuels (mainly fuel wood) was not through sustainable harvesting and thus net released carbon. Even if these fuels are omitted and only fossil fuels are included in the analysis, the strong trend of decarbonization since the rise of coal in the early 19 th century is still evident. Source: Grübler and Nakićenovic (1996).

particular technologies and infrastructures, the diffusion of energy sources follows a similar pattern. The market share of a fuel expands initially slowly as gradually expanding niche markets are filled; a more lengthy process of pervasive diffusion follows, eventually saturating and declining as a superior competitor enters and diffuses. Despite the simultaneous competition and interaction among many different sources of energy, each historical period is characterized by a clear dominance of a single energy source, which corresponds with the main technological clusters: fuelwood (and feed), followed by coal, and later by oil and natural gas. The rates for diffusion also correspond - all of the major fuels (wood, coal, oil, gas) required a century to achieve their ultimate saturation. The time constant for nuclear is not yet evident because it has low market share. Planned nuclear installations have fallen radically, which suggests that the energy source may be saturating. A new pulse for diffusion of nuclear power may require a new concept for reactors and their attendant cost and waste disposal problems. The existing nuclear power capacity diffused into service relatively rapidly because it could employ an existing large-scale infrastructure (ie, the electrical grid).

The consequence of shifting fuels is one of the most striking and consistent trends in the energy system: decarbonization. Each of the main fossil fuels has been progressively lighter in carbon per unit of energy released when burned. Coal, the dominant fuel from 1880 to 1950 , contains approximately one hydrogen per carbon atom. Today's dominant fuel, oil, contains two hydrogen atoms for every carbon. The hydrogen to carbon ratio in gas, the primary fuel whose share is rising most rapidly today, is four to one. More recently energy sources that have no direct carbon emissions such as hydropower and nuclear fission lighten our carbon diet. Hydrogen-rich fuels release more energy for every carbon atom that is oxidized to $\mathrm{CO}_{2}$ during combustion.

As shown in Fig. 13, the carbon to primary energy ratio for the USA has declined about $0.25 \%$ per year since 1800 . Worldwide, decarbonization of energy sources has occurred at a similar pace $(0.3 \%$ per year since 1850 ). In some countries decarbonization has been relatively rapid - in France, for example, since 1950 nuclear power has replaced fossil fuels as the supplier of nearly all electricity. Decarbonization of the economy has been even more dramatic because the decarbonization of energy sources (grams carbon per unit energy) has been multiplied by the decline in energy intensity of the economy (unit energy per dollar of economic output). Nearly every country's economy has shifted from energy-intensive industries to services; in addition, efficiency with which useful energy is generated from primary fuel sources has also risen in most countries over most periods of time. In the United States, the specific carbon dioxide emissions per unit of economic output has declined by almost an order of magnitude during the last two centuries, from about $2.5 \mathrm{~kg}$ of elemental carbon (C) per \$1 GDP (at 1990 prices) in 1800 to about $0.3 \mathrm{~kg} \mathrm{C}$ per $\$ 1$ GDP in 1990. In other terms, the economic "productivity" of carbon increased by more than $1 \%$ per year during the last two centuries.

Decarbonization has not autonomously eliminated carbon from the economy, but it has steadily softened the economy's impact on the atmosphere. For example, if the 
fuel mix of the 1920s powered the American economy today then annual carbon emissions would be more than 300 million metric tons (24\%) higher. For comparison, those averted emissions total more than today's annual industrial carbon emissions from Argentina, Brazil, Canada and Mexico combined. ${ }^{10}$

Although decarbonization is strongly evident in the historical record, most baseline scenarios project the opposite - stagnation or even re-carbonization with rising market shares for coal, which is the most carbon-intensive primary fuel. We return to those scenarios, especially the widely used IS92a baseline scenario of the Intergovernmental Panel on Climate Change (IPCC), after discussing the types of models that are often the foundation of scenario analysis. Technological change is poorly addressed in those models, and thus it is no surprise that model estimates of future decarbonization rates - which is one indicator of technological change - are not consistent with the historical record.

\subsection{Modeling the selection of technologies and their entironmental impacts}

Historical data indicate possible futures - such as decarbonization - but projecting the future by merely extending past historical trends is rarely adequate, especially when the underlying causal process are complex and liable to change. Thus causal models are often used to project scenarios for the future and to analyze policy choices. However, such models depend on good knowledge of the underlying processes. Because most energy analysts assume that technological change is hopelessly complex and shrouded in uncertainty, few rigorous causal models have been applied. Here we argue that the process of technological change is sufficiently well understood to make possible plausible models that endogenize technological change. Mathematical and computational barriers remain, but we illustrate the argument with one promising micro-scale approach that rigorously endogenizes the dynamic evolution of three electricity generation technologies. In the next section we address the arguments on a macro scale - in modeling and building scenarios for the world energy system - and show that even there better, though much more stylized, treatment of technological change is possible.

The controversy that surrounds modeling of technological change is endemic not only to energy and environmental assessments but also in economic analysis more generally. Treatment of technological change lies at the center of the debate between advocates of "old" and

\footnotetext{
${ }^{10}$ Dita from the Carbon Dioxide Information Analysis Center (CDIAC). Oak Ridge National Laboratory, Oak Ridge, USA. Values are expressed in tons of carbon; because those emissions are in the form of carbon dioxide. some studies report data in tons of carbon dioxide. To convert, multiply by $44 / 12$ (3.67).
}

"new" growth theory. ${ }^{11}$ Both sides agree that technology is central to long-term growth, but the mechanisms, and how to include them in formal models continue to be disputed. As Joseph A. Schumpeter observed long ago (in 1934), technological change arises from within the economic system and is central to its growth. In contrast, most models consider technological change as exogenous - in an expression coined by Bill Nordhaus, these models assume that new technologies fall into service like "leaves from autumn trees". In the field of global change, resolving these controversies and including endogenous technological change in models is especially important since the objective of this research - projecting plausible levels of future emissions, and assessing policies for controlling them - all depend principally on technology.

While the processes that lead to inventions remain largely opaque, it is now possible to model the factors that affect which innovations are selected for investments that lead to niche market applications, commercialization, and widespread adoption of technologies. The approach rests on two fundamental reasons for why private firms and the public (through government) invest in the pursuit of new technologies. (1) Investments into RD\&D and practical experience in commercial niche markets leads to learning, which improves costs and performance and thus makes technologies more competitive and offers profit opportunities for economic agents. (2) Uncertainty about the future - such as level of demand for technology services (eg, electricity generation), costs, and learning rates - lead firms and societies to hedge risks by investing in portfolios of new technologies with potentially useful attributes (Mansfield et al., 1972, 1977).

Despite overwhelming empirical evidence and solid theoretical underpinnings, learning phenomena - as discussed above - have been explicitly introduced into only a few models of intertemporal choice. A first detailed model formulation was suggested by Nordhaus and van der Heyden (1983) to assess the potential benefits of enhanced $\mathrm{R}$ and $\mathrm{D}$ efforts in new energy technology (the fast breeder reactor). Computational limitations at that time precluded the application of the model to a wider portfolio of technologies in the model formulation. A first full-scale operational optimization model incorporating systematic technological learning was first developed at IIASA (Messner, 1997; Nakićenović, 1996). Conventional learning curves for a number of advanced electricity generating technologies were introduced into a linear programming model of the global energy system. Because learning rates were assumed ex ante, future technology costs in the model depended solely on the amount of intervening investments in installed capacity. Given specific (known) learning rates, the model determined the optimal investment profile that would yield future

\footnotetext{
${ }^{11}$ See references in note. 2.
} 
technology improvements via learning by doing. (RD\&D that did not directly result in an increase in installed capacity was excluded as a source of technological change in the model.) That model confirmed the expectation that it can be economically optimal to invest into costly, immature technologies in anticipation of improvements through technological learning. Absent such prior investment, new technologies did not become competitive in the future - rather, the technological system remained "locked-in" to existing technologies, productivity did not increase, and the portfolio of available cost-effective technologies remained limited and insufficient to address possible long-run resource or emissions constraints. In such cases, the only options for addressing those futures in such a technology optimization model (and in real society) entailed resorting to currently known expensive technological alternatives ("backstops"), leading to economic losses, such as lower consumption and welfare.

Today, few of the main models used to assess the level and costs of controlling future carbon emissions rigorously employs a learning curve formulation. Thus few of the models internally generate the investments needed to yield new commercial technologies. Rather, future costs are assumed as exogenous model inputs and are independent from any intervening efforts and costs. ${ }^{12}$ We suggest that if technological change is to be adequately included then models must explicitly link investment decisions to changes in technology characteristics. The learning curve concept is one simple device for doing this. But the simple application of learning curves confronts two shortcomings. One is that only traditional learning curves have been employed in these models and thus cost improvements due to RD\&D have been ignored. As shown earlier, especially at the stages of innovation and niche market commercialization, RD\&D is a significant contributor to improved cost and performance. The other is that the empirical literature suggests a range of learning rates that might be expected, but exact rate for particular technologies and processes remains of course uncertain, and thus the learning rate - ie, returns from investments - must be modeled as uncertain.

Uncertainty is pervasive when firms and societies make technological choices and thus must be reflected throughout models used in technological forecasting. The importance of technological uncertainty has been recognized and explored ever since the earliest days of global environmental modeling (eg. Nordhaus, 1973; Starr and Rudman, 1973). Different approaches have been followed for analyzing the impacts of technological

\footnotetext{
"Sume models deploy additional exogenous constraints to "force" models into earlier investments into expensive technologies before cheaper ones become available. See, for example. Manne and Richels (1997).
}

uncertainty including the formulation of alternative scenarios (eg, Nakićenović et al, 1995), analysis of model sensitivity to input parameters (eg, Nordhaus, 1973; Nordhaus, 1979), and sensitivity analysis based on expert polls or Delphi-type methods (eg, Manne and Richels, 1994). Yet in practice these studies were principally based on adaptations of the deterministic optimization models. ${ }^{13}$

That modeling approach has allowed assessment of the sensitivity of models outcomes to variations in uncertain model input parameters or some exploration of optimal management strategies, such as strategies that emphasize adjustment of policy decisions over time as uncertainties are resolved (Hammit et al, 1992; Lempert et al, 1996) (more generally see Holling, 1978, and Walters, 1986). But the deterministic framework is unable to identify investment strategies that are robust or "optimal" when decision-makers simultaneously face many uncertain choices because uncertainty (stochasticity) is not built into the decision framework. In the model of endogenous technological change explored here, uncertainty translates into both economic risks and opportunities, and both are directly endogenized into the model's decision rules and the resulting technology strategies.

True endogenization of uncertainty and learning phenomena has required the application of models that are mathematically cumbersome involving simultaneously stochasticity and recursive formulations. Moreover, technological learning is a classical example of increasing returns, ie, the more learning takes place, the better a technology's performance. Thus the mathematical solutions are non-convex - the more investment the lower the costs - which is especially difficult to handle in traditional optimization models and algorithms. A general methodology for handling uncertainty in optimization problems through a stochastic sampling technique was described in Ermoliev and Wets (1988) and an improved algorithm was developed by Ermoliev (personal communication). That stochastic optimization framework has been applied in the MESSAGE technological optimization model for several technologies by the IIASA energy research group. ${ }^{14}$ Similar mathematical and

\footnotetext{
${ }^{13}$ For example, Manne and Richels (1994). Examples of models incorporating stochasticity include Kolstad (1993) and Fragnière, and Haurie (1995).

${ }^{14}$ See Golodnikov et al (1995), Messner et al (1996) and Messner (1997). Fragnière and Haurie (1995) have applied a similar framework using the MARKAL optimization energy model. The two stochastic modeling approaches are however different. The stochastic MARKAL model takes the classical stochastic approach towards decisions under uncertainty: assuming that at some future date, uncertainty (on technology costs, environmental limits, etc.) becomes resolved. The stochastic MESSAGE model does not rely on the assumption that at a given date uncertainty disappears altogether. Rather the model calculates an optimal diversification strategy in face of persistent uncertainty by integrating stochastically drawn samples into an overall objective function.
} 
conceptual problems also have been partially addressed in work on "path-dependence," in which initial decisions lead to multiplying network effects and increasing returns from the adoption of a particular technological solution (Cowan, 1991).

\subsubsection{A model of technological change through uncertain learning}

The model with endogenous technological change developed at IIASA overcomes the main failings of existing approaches - the inadequate representation of learning as a consequence of both RD\&D investments and cumulative commercial experience (learning by doing), as well as the failure to incorporate uncertainty in models of technological learning (Grübler and Gritsevskii, 1997). The intention is to extend the traditional approach to modeling energy technologies in which technical change is induced only by relative resource and factor endowments and price changes. ${ }^{15}$ In contrast, the IIASA approach yields an optimization model that can make forward-looking investments that are needed to yield (uncertain) learning and cost reductions for particular technologies. Thus new technology may be rendered competitive and is selected for widespread commercial application. Traditional optimization models make no such anticipatory investments. ${ }^{16}$

The conceptually simple model represents a demand for one homogenous good, electricity. Total demand rises over time in proportion to total demand in the widely used IPCC and IIASA/World Energy Council (IIASA/WEC) "high demand" scenarios. ${ }^{17}$ There exists one primary resource (coal), whose extraction costs increase over time as a function of resource depletion, while being sufficiently large that absolute resource scarcities are not encountered over the entire simulation horizon (200 yr).

Three technologies - "Mature", "Incremental", and "Radical" - are available that can supply the demand for electricity. The stages of technological development for those correspond with the same-named stages in Table 1.

\footnotetext{
$15 \mathrm{eg}$. Hayami and Ruttan (1985); for overviews see Binswanger (1978). Jorgenson and Fraumeni (1981) and Ruttan (1996).

it Linear programming models typically include constraints on the rate at which a new technology can enter the marketplace; without such constraints the model would instantly switch from one technology to another as soon as the latter is less costly (for additional discussion, see Fragniere and Haurie (1995)). Thus the optimal solution to these models often entails earlier investments into new technologies so that rate constraints are met. Such investments are the consequence of the model formulation. not because the model anticipates (as does a profitseeking firm) that an investment will make a technology more competitive in the future.

${ }^{17}$ Demand is scaled to economic growth in the Series A scenarios of the World Energy Council (WEC) and the IS92e and $f$ scenarios of the Intergovernmental Panel on Climate Change (IPCC). For IPCC see Pepper et al (1992); for IIIASA-WEC see Nakicenovic et al (1995).
}

The current costs of each technology are assumed to be known perfectly, but the potentials for future learning vary markedly as a function of the uncertainty in learning rates. ${ }^{18}$ The Mature technology is assumed to be in widespread diffusion; its characteristics (costs and resource conversion efficiency) do not change over time. The Incremental technology has a slight efficiency advantage over the mature technology, is initially more costly (by a factor of 2), and has a potential mean learning rate assumed at $10 \%$ for each doubling of cumulative production capacity. The Radical technology hardly requires any resource inputs and thus offers a substantial efficiency premium. Because it is a radical innovation it is also a factor of 40 more costly than the Mature technology. However, as common with radical new technologies, it has high potential for technological learning - we assume a mean learning rate of $30 \%$ (per doubling of capacity), which is consistent with historical examples of radical technological change reviewed earlier. For both the Incremental and Radical technologies the rates of learning are treated as uncertain, represented by a lognormal distribution function around the mean value. For the Radical technology the variance of the distribution function is three times that of the Incremental techno$\log y$, reflecting the much higher spread of uncertainty associated with radical technologies.

These three technologies correspond with three prominent electricity technologies available today. Current coal-fired power stations, with thermal efficiency of $30 \%$, and costs of US $\$ 1000 / \mathrm{kW}(\mathrm{e})$, are a typical mature technology. An incremental improvement is represented by an advanced coal-fired power station (eg, with fluidized bed boilers and all basic environmental equipment such as precipitators and $\mathrm{SO}_{x}$ and $\mathrm{NO}_{x}$ removal units, but not $\mathrm{CO}_{2}$ removal), with thermal efficiency of $40 \%$ and initial costs of US\$2000/ $\mathrm{kW}$ (e). The coal resource in our model is consistent with known world reserves and resources of coal, which exceed 200 years and exhibit rising extraction costs as the most accessible and highest quality reserves are depleted. The Radical technology corresponds with photovoltaic (PV) cells, which use a basically free resource (sunlight) but are initially very costly (we use a starting value of US $\$ 40,000 \mathrm{USD} / \mathrm{kW}(\mathrm{e})$ characteristic of PV costs in the early 1970s).

For each run in a large sample $N$ the stochastic model samples a value for each of the uncertain parameters. The

\footnotetext{
${ }^{18}$ Current prices of new technologies (which are costly but decline with learning) are assumed to be known perfectly (the market provides for the mechanism to reduce any uncertainty on current costs: actual investment). The model treats future learning rates as uncertain. Hence future technology costs are a function of (uncertain) learning rates and the resulting intertemporal optimum investment profile the model determines for any given (stochastic draw) of the learning rate. No further exogenous cost inputs enter the model. The model also does not require exogenous specification of a future "floor" price, ie a lower bound to which costs decline as a result of technological learning.
} 


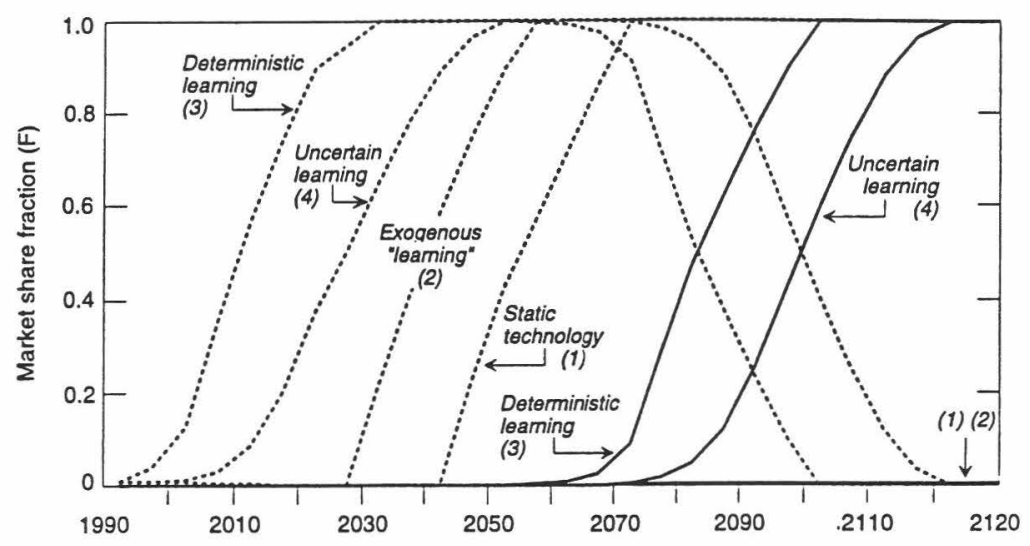

Fig. 14. A simple optimization model with endogenous technological change. The figure shows the fraction of total installed generating capacity supplied by alternative new electricity generating technologies: Incremental (dashed lines) and Radical (solid lines). These differ in their current costs as well as possibilities for future cost reductions (learning). Four simulation runs are shown: (1) static technology costs and performance for all technologies, which yields technological change only in response to resource depletion; (2) exogenously given cost improvements for Incremental technologies; (3) certain (deterministic) learning rates for Incremental and Radical technologies; and (4) uncertain learning rates for Incremental and Radical technologies. Without endogenous learning, the Radical technology remains at zero market share. When the rate of learning is certain the optimal solution is to invest heavily and early into new technologies because the resulting cost declines render the technology quickly competitive. When learning rates are uncertain, the optimal solution is more cautious. Market shares for the existing, Mature technology are not shown on this figure. Source: Grübler and Gritsevskii (1997).

model then calculates the minimum cost to build the installed capacity for each of the three technologies needed to satisfy the total demand for electricity. (For simplification, we assume $100 \%$ capacity utilization for all three technologies.) That calculation includes the optimal investment profile that yields future cost reductions in the Incremental and Radical technologies, which is necessary to make those new technologies competitive with the existing Mature technology. Because the learning rates are stochastic, the future RD\&D and investment costs needed to make the incremental or radical technology competitive in the future is also a stochastic function of the intervening cumulative investments. Thus actual costs in any run of sample $N$ may deviate from the expected costs, which arise by applying the mean learning rate.

The optimal solution for the entire sample is calculated by finding the minimum of the overall objective function, which integrates all the realized outcomes from each of the stochastic draws in sample $N$. Because each individual draw deviates from the expected model outcome we need a weighting procedure for integration of all these different realized individual model solutions into the overall objective function. The overall objective function incorporates the objective function of the mean (expected) value expanded to include two additional terms. (1) If the realized costs in a draw are less than expected, the resulting cost difference (savings) is added to the objective function (i.e. subtracted). (2) If costs exceed expectations, the resulting cost difference (cost overrun) is also added to the objective function, but quadratically. This reflects our assumption that underestimating future costs is penalized more heavily in competitive markets than cost overestimation. Cost underestimation (leading to higher costs than expected and higher than one's competitors) risks the very survival on the market, whereas cost overestimation, which leads to lower future technology costs than expected yields merely higher profits than expected. In other words, our model is conservative - it assumes that commercial decision-makers give paramount value to survival. The model performs a simultaneous sampling of parameter values. All realized outcomes (plus and minus the two additional terms explained above) of the individual draws of sample $N$ are integrated into the overall objective function. The resulting overall minimum solution represents the optimal technological diversification strategy vis a vis the (uncertain) economic returns on learning that result from R\&D and investment into technology demonstration and niche markets. ${ }^{19}$

Fig. 14 shows results - the share of electricity supplied by each technology - for four of the simulations. If technology is treated as static (no learning) then generally neither the Incremental nor the Radical technology is selected, and $100 \%$ of the market is supplied by the

\footnotetext{
${ }^{19}$ For each draw, the model solves simultaneously the non-convex and non-smooth optimization problem by applying a combination of a simple global procedure, a modified Nelder-Mead algorithm, and a BFGS quasi-Newton minimization (see Grübler \& Gritsevskii, 1997).
} 


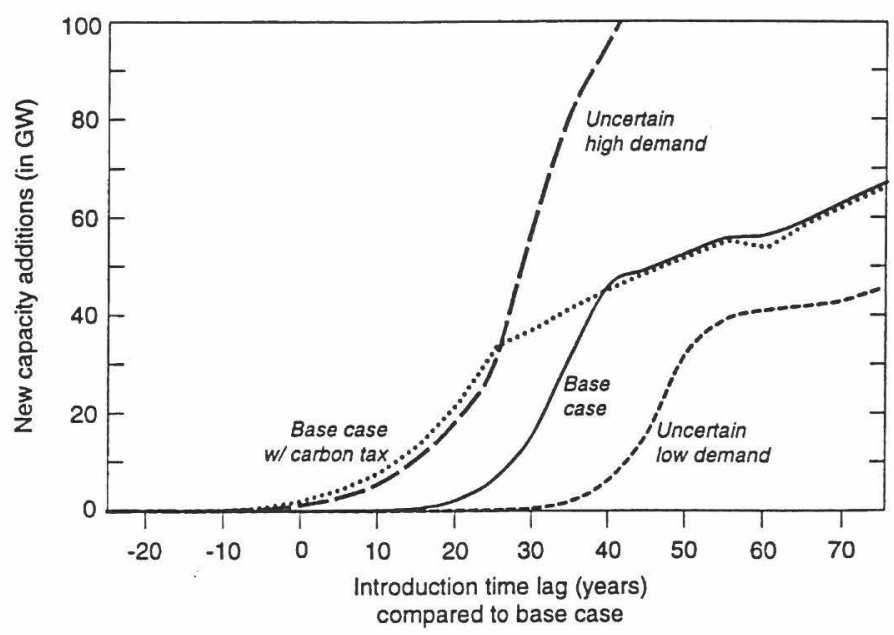

Fig. 15. Endogenous technological change with carbon constraints and other uncertainties. Figure shows new capacity additions for three simulation runs: (1) Base Case with cost improvements due to uncertain rates of learning (same as run 4 in Fig. 14); (2) addition of an uncertain carbon constraint (see text); and (3) addition of the possibility that demand for electricity will be substantially higher or lower than expected in the Base Case simulation.

Source: Grübler and Gritserskii (1997).

Mature technology. The first simulation (labeled "static technology") portrays technological change as in models that employ the concept of a "backstop" technology. The Incremental technology diffuses eventually not by improved performance but as a result of resource depletion that raises energy prices, making the Incremental technology commercially viable due to exogenous developments. A second run, which we term "exogenous learning", assumes that the cost of the Incremental technology falls at an exogenously determined rate. The result is a pattern that is again typical of optimization models that employ exogenous technological change: at some point in the future a new technology massively enters the picture due to an exogenously assumed cost reduction. Large-scale technology optimization models, which are widely used to assess the costs of abating various environmental problems, display similar "flip-flop" behavior. Published runs typically do not illustrate such behavior only because additional constraints or restrictions on the rate and pattern of technological diffusion, tuned according to the modelers sense of the historical record, are applied to make the outputs appear more realistic. Like sausage, the final product is evidently wholesome but the method of producing tasty results is best left shrouded in mystery.

A third run in Fig. 14 shows the effect of adding learning with zero uncertainty - what we term "deterministic (certain) learning". A fourth run illustrates "uncertain learning" - it fully incorporates uncertainty (stochasticity) and learning, and thus is the full model of endogenous technological change. Note that the addition of learning in both of these runs leads the Radical technology to enter the market. In the deterministic case with no uncertainty a new technology enters the market earlier and diffuses faster. When learning is uncertain, diffusion is more gradual and market entry is later. Only the latter case exhibits the S-shaped diffusion patterns evident in the historical record. Both learning and uncertainty are essential to building a model that endogenously produces results that reflect how technologies enter and diffuse into markets in the real world.

Fig. 15 shows the results when an uncertain possibility of a constraint on emissions - represented by a carbon tax - is added to the model. For illustration, we assume that there is a one in three chance that some tax would be implemented sometime in the future; if the tax is implemented, we assume that the probability of introduction by 2050 is $50 \%$, rising to $99 \%$ by the year 2100 . The lcvel of the tax is also uncertain - we draw a Weibull distribution around the mean expected value of the tax (US\$50 per ton carbon), with a $99 \%$ probability that it would not exceed US\$125 per ton carbon. As expected, the existence of an uncertain environmental constraint alters the patterns of technological change substantially. Investments in new technologies are shifted earlier in time to prepare for the possibility of facing a costly future with environmental constraints. For comparison, Fig. 15 also shows the results if future demand is treated as uncertain - higher or lower - than in the base case runs in Fig. 14. These three types of uncertainty shown in Figs. 14 and 15 - learning rates, emissions constraints, and demand - are the most important unknowns for the energy sector. In 
all three, earlier and longer investments in new technologies is the result when the need for technologies with new attributes looms large.

The goal with this exercise is not a full-blown realistic model of technological change for all aspects of the energy system. Rather, at this initial stage, the purpose has been to develop a simple model that demonstrates the feasibility of a mathematical formulation. Even with this simple model, three important points emerge. First, radical technological change does not occur in the model if there is no endogenous mechanism for improving future performance and costs (unless one ventures into imposing daring exogenous technological discontinuities into the model). It is hardly surprising that if technological change is modeled as a certain, gradual and autonomous process - as it is in most energy technology models and nearly all macroeconomic models - then the computed technological dynamics evolve slowly, if at all, and the future is assumed to look much like the present. (Nonetheless, not all parameters are endogenous to the model; the sensitivity of the results to the exogenous parameters is examined elsewhere. ${ }^{20}$ )

Second, only by including uncertainty and learning does the model display S-shaped diffusion curves that are similar to those that have been observed empirically. Uncertain learning leads to risk minimization and hedging strategies-ie to initial investments that make new technologies more competitive and allows them to enter niche markets. Modeling uncertainty in other parameters, such as the possibility of higher energy demand,

\footnotetext{
${ }^{20} \mathrm{~A}$ model that incorporates increasing returns is obviously highly sensitive to the parameter values adopted in the simulations. Sensitivity analyses showed that model outcomes depended most heavily on the assumed learning rates (treated endogenously in the model), followed by uncertainties in energy demand. and the possible (uncertain) existence of environmental constraints. Conversely, varying initial costs mattered only for some combinations. For instance, varying the initial costs from 10,000 to 30,000 for a mean learning rate of $30 \%$ delays the economic break-even point of the Revolutionary technology by more than five decades Initial costs were not treated as uncertain, - as in reality uncertainty can be reduced immediately by placing of an order. The group also investigated sensitivity to changes in the discount rate (results in figure are based on a $5 \%$ discount rate). As expected, higher discount rates result in postponed technological investment, experimentation and learning.

Maintaining the same variance in the uncertainty of the learning rate but changing the distribution (eg. from the symmetric lognormal to asymmetric distributions with long tails like Weibull or Gamma distributions) were also found to influence the model outcomes. Even with the same variance. the model is sensitive to the existence of even extremely low-probability outlier values. For example, including the very small possibility of an extreme high learning rate, the model moves in direction of earlier and higher investments in new technology. Typically the penetration curve for "uncertain learning" (see Fig. 15) is shifted left by one to two decades. Even a slight chance of a big payoff results in accelerated investment. (The converse is not fully symmetrical because the objective function gives special aversion to under-estimating actual costs.)
}

leads to similar up-front investments and S-shaped diffusion patterns. When full uncertainty is included (e.g., the runs in Fig. 15) the results can be interpreted as an optimal technology diversification strategy in the face of pervasive uncertainty.

Third, the model autonomously produces "surprising" results. Even without carbon or significant resource constraints, plausible assumptions in the model lead to the widespread use of a zero carbon (photovoltaic) energy source. These surprises are even more abundant when examining individual runs rather than the optimal solution for the whole sample runs $N$. As the treatment of technology in models improves, the results become less deterministic. As in the real world, the future can easily hold dramatic changes in technological regimes that could eliminate or create whole classes of environmental problems. While the potential for surprise has long been recognized, until now plausible models could not simultaneously generate realistic technology dynamics and autonomous surprises. The approach thus addresses an important critique of existing models and other analytical methods - the tendency to ignore factors that cause discontinuities and surprises (Brooks, 1986).

\subsection{Models and scenarios for the world energy system}

In previous sections we have shown that it is possible to simulate how changing costs affect technological choices at the micro level - i.e., to model the selection among a handful of competing technologies in an isolated market. But at larger scales - the energy system of a whole economy, region or the globe - models that fully and realistically endogenize technological change are still impossible. Relationships between the wide array of factors that determine technological choices are poorly understood, and the need to model decision making by thousands of agents and for hundreds of possible technology combinations exceeds available modeling and computational capacity.

Because uncertainties abound at the macro scale, almost every model-based analysis employs scenarios. Scenarios bound possible futures, and they make it possible to focus attention on analytically tractable issues, such as how the adjustment of one or more "policy" variables causes changes in emissions from a baseline scenario. Because scenarios are the backbone of macro analysis, here we focus on ways to incorporate technological dynamics into scenarios by incorporating technological change into the macro modeling tools that are used to create scenarios. We argue that the existing modeling tools fail to reflect well-established patterns of technological change, and thus the scenarios that they generate are often inconsistent with plausible technological futures. The resulting policy analysis is misleading. 
Most scenario analysis begins with a "business as usual" baseline scenario - the result of a model run that incorporates no particular drastic changes in technologies or policies. The IS92a scenario of the Intergovernmental Panel on Climate Change (IPCC), the most widely used such baseline scenario, illustrates the generic approach (see Table 3). Worldwide economic growth is high $(2.2 \%$ per year on average from 1990 to 2100); developing countries, especially in Asia, grow more rapidly than the industrialized countries. Radical technological change does not occur. Rather, the future is assumed to be merely the result of compounded marginal changes to today's energy system. For example, just as coal was the principal fossil energy source some $50 \mathrm{yr}$ ago, in 2100 the world of IS92a is also principally (47\%) powered by coal. The ratio of sulfur emissions to carbon is also high, and thus the environmental effects of sulfur, such as acid rain, would be severe in the world of IS92a. Energy consumption per unit of economic output declines over $70 \%$ because the economy as a whole is projected to become more efficient and structural change has favored less energy-intensive services over industrial manufacturing, but the energy delivered is just as carbon-intensive as today. Decarbonization, though strongly evident in the historical record, is practically nonexistent: in 1990 every $10^{6} \mathrm{~J}(\mathrm{MJ})$ of primary energy released $17.4 \mathrm{~g}$ of carbon, which decreases slightly to $14.1 \mathrm{~g}$ of carbon per MJ of primary energy by 2050 . Thereafter, decarbonization stagnates and reaches a value of $13.6 \mathrm{~g}$ $\mathrm{C} / \mathrm{MJ}$ by 2100 ). This static view of technological change is hardly surprising since the models used to create the IS92a scenario do not capture the dynamics of technological change.

To illustrate the consequences of improving the representation of technological change, working with collaborators at IIASA we have linked a conventional macroeconomic model with a model of regional and global energy systems. The macroeconomic model - an 11 region version of the widely used MACRO model (Manne and Richels, 1992) - computes the size of the economy, investment flows, and demand for electric and non-electric energy. Such a macrocconomic model is broadly similar to other macro models used for scenario analysis - its strength is that it treats the economy of coherent regions of the world in an integrated fashion and estimates demand for energy. Its weakness, also shared by the models typically used in macroeconomic scenario analysis, is that it has little resolution of technological choices. Yet the choice of technologies determines emissions and environmental impacts. The IIASA team has addressed that weakness by linking MACRO with MESSAGE IV, the latest version of a widely used linear programming model that optimizes the technology system needed to satisfy a given demand for electric and non-electric energy (Messner and Strubegger, 1995). MESSAGE IV selects from a large portfolio of current and future tech- nologies, whose cost and system characteristics are derived from the IIASA CO2DB technology inventory database that comprises some 1600 technologies. MESSAGE IV computes the minimum (discounted $5 \%$ for all runs presented here) total systems costs (including investment and operating costs) needed to satisfy the projected demand from the MACRO model. The approach partially solves the classic "top-down" and "bottom-up" dichotomy of energy models. It allows estimation of the economic losses that result, e.g., when carbon constraints are applied to the economy (a strength of top-down, macroeconomic models) as well as the minimum cost suite of technologies needed to meet a given constraint (a strength of bottom-up technological system models). For more on the methodology of linking the models see Wene (1995). Because it employs a model of whole energy systems from technologies for production of primary energy through final energy consumption by end-use technologies - the approach accounts for the synergies and infrastructures that define technological clusters and given choices of individual technologies.

The details of the models, resource constraints, population estimates and other factors are described elsewhere (Nakićenovic et al., 1998). Here we use the linked model to illustrate a simple point: a plausible change in the representation of technology in such models can lead to radical changes in the computed environmental effects. That change is impossible to implement in conventional macroeconomic models that ignore the competition between technologies to supply energy.

First we generated a baseline scenario by mimicking the approach in existing macroeconomic models and "business as usual" scenarios. We assume that trade liberalization continues and thus the world economy grows rapidly - in 2100 the economy is nearly twenty times larger than in 1990. As in other high demand baseline scenarios, we allow gradual and modest improvements in the performance of end-use technologies. The economy as a whole continues the structural change from manufacturing to services as income rises. Thus, as in other models, the energy intensity of production declines: in $199013.1 \mathrm{MJ}$ of final energy were needed to produce one dollar of economic output; by 2100 only one-fifth the level of energy $(2.5 \mathrm{MJ})$ would be needed in our scenario. Global energy needs thus increase less than a factor of 4 while the global economy grows nearly 20 -fold. Consistent with this trend towards higher efficiency, the shift to higher quality final energy carriers also continues - the share of final energy supplied by electricity rises from $13 \%$ in 1990 to $35 \%$ by 2100 . Overall, the efficiency of converting primary energy to GDP improves $1.3 \%$ per year, comparable with the historically observed rate and also with the $1 \%$ per year rate of "autonomous energy efficiency improvement (AEEI)" that is used in many macroeconomic models (Manne and Richels, 1992). As in other baseline scenarios such as 
IS92a, the scenario does not assume any radical technological changes in energy supply technologies and accessibility of fossil energy resources. Hence, as in IS92a, the future world is mainly powered by coal, as conventional oil and gas become depleted and new, alternative energy technologies are not sufficiently developed and remain too expensive to compete with coal. By 2020 coal has surpassed oil as the single largest source of primary energy. In 2100 nearly half $(42 \%)$ of primary energy is from coal, and coal is the dominant fuel for electricity generation. The environmental consequences are profound: emissions of carbon dioxide and sulfur are 4 times 1990 levels. In Asia, sulfur emissions, which already are causing health and environmental problems, rise five-fold.

Next the IIASA team made one revision: the addition of technological learning. The results show more rapid technological dynamics and different technological choices than in the baseline scenario. As in the earlier model that endogenized technological learning for a single agent selecting between three technologies, we did this by dividing all technologies considered in the MESSAGE model into three categories - mature (existing), incremental and radical. The investment cost for existing technologies does not vary; the cost of investing in incremental technologies declines $15 \%$ for every doubling of installed capacity; and the cost of radical technologies declines $30 \%$ for every doubling. For example, in this "dynamic technology (DT)" scenario advanced coal power plants (an "incremental technology") decline in cost from US\$1650 per kW(e) of installed capacity to US\$1200/ $\mathrm{kW}(\mathrm{e})$ while total installed capacity more than doubles. Solar photovoltaics (a "radical" technology) decline in cost from US\$5000/ $\mathrm{kW}$ (e) in 1990 to approximately US $5500 \mathrm{~kW}(\mathrm{e})$ as installed photovoltaic capacity rises from practically zero today to some $100 \mathrm{GW}$ by the end of the 21 st century.

(At present it is only possible to endogenize learning curves in a one-region model that includes a few technologies (Messner, 1997). Adding learning curves to a model of 11 regions with hundreds of technologies remains practically impossible. Thus for the full model discussed here the IIASA team added illustrative "learning" through an iterative process that was consistent with the principle of learning but did not confront the mathcmatical and computational barriers to a hard-wired full learning model. We first used a simple spreadsheet model to calculate the investment profiles and decline in costs for each of the incremental and radical technologies consistent with the assumed learning curve parameters. With these cost data the MESSAGE model was run again and the resulting investment profiles of the model were compared with those calculated by the learning curve model. For all of the incremental and radical technologies, the actual investment costs made by MESSAGE were within $3-5 \%$ of that needed to sustain the appropriate learning rate $(15 \%$ for incremental and $30 \%$ for radical technologies ${ }^{21}$ ).

The result of these simple adjustments to the representation of technology has little effect on the macroeconomic outputs of the linked model. Because energy costs (per unit of economic output) are lower and investment is higher, the world economy is slightly larger than in the baseline scenario, which already envisioned even more robust economic growth than in the bullish IS92a scenario. But unlike our baseline and IS92a baseline scenario, the wealthy future of the DT scenario is also relatively clean. Despite declining costs for advanced coal power plants, MESSAGE shifts to even less costly advanced gas plants (which are already abundant in today's energy markets) and then to solar and other zero carbon fuels. Until 2060 the share of gas as a transition fuel for electric generation rises. Coal and biomass, which supply a growing share of transport fuel (methanol) and electricity in the baseline scenario, give way to solar-based energy sources, including hydrogen, and new nuclear power technologies such as inherently safe, modular, high temperature reactor designs. By 2100 decentralized (ie, non-grid) energy generation technologies supply two-thirds of all electricity demand. This category consists of on-site solar photovoltaics $(30 \%)$, hydrogen cogeneration $(25 \%)$, and hydrogen fuel cell vehicles that generate household electricity when parked $(45 \%)$. Hydrogen itself can be generated in many ways - the most efficient emit little carbon and sulfur (eg, steam reforming of natural gas) or no carbon at all (eg, when based on solar or nuclear primary energy).

The impact of the different technologies in the DT scenario on environmental quality is dramatic. Sulfur emissions decline six-fold from 1990 levels by 2100 , and world carbon emissions rise only slightly (20\%). By 2100 , only $4 \mathrm{~g} \mathrm{C}$ are released per MJ of primary energy supply, which is an average rate of decarbonization of $1.3 \%$ per year (four times the historical value). With the widely used MAGICC climate model $^{22}$ we have

\footnotetext{
${ }^{21}$ It should be noted that because MESSAGE is a linear programming model that it includes typical constraints on the rate of market penetration, without which the model would rapidly switch from one technology to another (sometimes overnight) as soon as the new technology is cost-competitive. Because MESSAGE has perfect foresight. these constraints lead to pre-competitive investments in new technology so that future market penetration constraints can be met. Thus the time path of actual technology investments, which is broadly consistent with that observed in the real world, is more an artifact of the assumptions that underpin the linear programming method. Consequently we have used the simple learning model to verify not only that the annual investment costs are consistent but, more importantly, that the total and multi-decade costs are consistent with the learning rates that we employ. These penetration constraints are not needed if a learning curve is used directly in the optimization model (see Messner, 1997) and in the micro model presented in this paper, but for the larger scale model such modeling tricks remain essential.

${ }^{22}$ The carbon model is from Wigley $(1991,1993)$; the climate model is from Wigley and Raper (1987, 1992).
} 
Table 3

Four global scenarios and the importance of technological change. Conventional baseline ("no policy") scenarios reflect only gradual changes or static technology - here, we show the widely cited IPCC IS92a and WEC/IIASA Series A2 (high coal) baseline scenarios. In these scenarios the future energy system appears similar to the present and is thus heavily based on coal. Linking a macroeconomic model with a model of technological choice (eg, MESSAGE) can generate radically different results. We show a baseline scenario from the MACRO-MESSAGE model that is designed to mimic other baseline scenarios. Then we show a "DT" scenario in which learning curves have been stylistically added with the result that technology is more dynamic and emissions are lower, even in the absence of carbon constraints.

\begin{tabular}{|c|c|c|c|c|c|}
\hline \multirow[t]{2}{*}{ Scenario attributes } & \multirow[t]{2}{*}{$\begin{array}{l}1990 \text { levels } \\
\text { (observed) }\end{array}$} & \multicolumn{2}{|c|}{ Conventional baseline scenarios } & \multicolumn{2}{|c|}{$\begin{array}{l}\text { MACRO-MESSAGE scenarios } \\
\text { (this paper) }\end{array}$} \\
\hline & & IPCC IS92a & WEC/IIASA Series A2 & Baseline & $\begin{array}{l}\text { Dynamic technology } \\
\text { (DT) }\end{array}$ \\
\hline $\begin{array}{l}\text { World income ( } 10^{12} 1990 \text { USD, } \\
\text { market exchange rates) }\end{array}$ & 20.9 & & & & \\
\hline $2050(\% \text { growth })^{a}$ & & $92(2.6 \%)$ & $100(2.7 \%)$ & $117(2.9 \%)$ & $118(2.9 \%)$ \\
\hline $2100(\% \text { growth })^{a}$ & & $240(2.3 \%)$ & $310(2.5 \%)$ & $384(2.7 \%)$ & $393(2.7 \%)$ \\
\hline Final energy intensity & & & & & \\
\hline$\left(10^{6} \mathrm{j} \text { per } 1990 \text { USD }\right)^{\mathrm{b}}$ & 13.1 & & & & \\
\hline 2050 & & 6.8 & 7.2 & 5.8 & 5.7 \\
\hline 2100 & & 3.6 & 3.5 & 2.5 & 2.8 \\
\hline Primary energy $\left(10^{18} \mathrm{~J}\right)$ & 381 & & & & \\
\hline 2050 & & 930 & 1040 & 1100 & 990 \\
\hline 2100 & & 1500 & 1900 & 1700 & 1800 \\
\hline $\begin{array}{l}\text { Primary energy, Share of coal and } \\
\text { zero carbon }\end{array}$ & $24 \% / 22 \%$ & & & & \\
\hline 2050 & & $37 \% / 21 \%$ & $37 \% / 27 \%$ & $31 \% / 32 \%$ & $4 \% / 50 \%$ \\
\hline 2100 & & $47 \% / 30 \%$ & $38 \% / 51 \%$ & $42 \% / 46 \%$ & $0.4 \% / 77 \%$ \\
\hline Carbon emissions $\left(10^{15} \mathrm{~g} \mathrm{C}\right)^{\mathrm{d}}$ & 6.2 & & & & \\
\hline 2050 & & 13 & 15.1 & 16 & 9.5 \\
\hline 2100 & & 20 & 22 & 25 & 8.5 \\
\hline Sulfur eissions $\left(10^{12} \mathrm{~g} \mathrm{~S}\right)^{\mathrm{d}}$ & 60 & & & & \\
\hline 2050 & & 101 & 85 & 170 & 17 \\
\hline 2100 & & 123 & 160 & 240 & 11 \\
\hline Sulfur carbon ratio ( $\mathrm{g} \mathrm{S}$ per $\mathrm{kg} \mathrm{C}$ ) & 10 & & & & \\
\hline 2050 & & 10 & 5.7 & 11 & 1.8 \\
\hline 2100 & & 6.2 & 7.4 & 9.6 & 1.3 \\
\hline Radiative forcing $\left(W^{\prime} \mathrm{m}^{-2}\right)^{c}$ & $2.6-1.3=1.3^{r}$ & & & & \\
\hline 2050 & & $5.7-2=3.7$ & $6-1.5=4.5$ & $6.5-2.4=4.1$ & $5.6-0.9=4.7$ \\
\hline 2100 & & $8.2-2=6.2$ & $9-2.3=6.7$ & $10.3-2.9=7.4$ & $6.9-0.8=6.1$ \\
\hline
\end{tabular}

a Averige global annual growth rate since 1990.

'Intensity of final energy is a measure of the economy's efficiency; it reflects direct improvements in the efficiency with which energy is used to make a given economic output (product or service) as well as structural change (eg. shifts from energy-intensive manufacturing to service-oriented economy). IPCC values are for "secondary energy," which is comparable in definition to "final energy" in the WEC and IIASA studies (ie, heat content of energy after conversion and distribution).

"These two parameters are indicators of change in technology and the fuel mix. For IPCC, "coal" primary energy is not reported; the values here are for "solid" energy. "zero carbon" is assumed to be nuclear and renewable energy; in none of the scenarios is carbon "scrubbed" from flue gases.

${ }^{\mathrm{d}} \mathrm{Carbon}$ and sulfur from industrial processes only, mainly the burning of fossil fuels and biomass for energy and as feedstocks. IPCC reports slightly higher $\left(70 \times 10^{12} \mathrm{~g} \mathrm{~S}\right)$ anthropogenic emissions of sulfur.

'Increase in radiative forcing since preindustrial era $(\sim 1765)$. Cells show net increase in radiative forcing from carbon and other greenhouse gases (including indirect effects such as stratospheric water vapor and ozone) minus the negative forcing from sulfur (direct and indirect effects). Values computed with MAGICC model and added to 1990 forcing levels to yield total increase in forcing.

'Values for 1990 used in calculations here; however, note that sulfur forcing is uncertain. IPCC (1995, Fig. 6.19) reports less intense negative sulfur forcing $\left(-0.8 \mathrm{~W} \mathrm{~m}^{-2}\right)$

estimated the future concentration of carbon dioxide and greenhouse forcing. In the baseline scenario carbon concentrations rise to 800 parts per million by volume (ppmv) from 355 ppmv in 1990. Carbon concentrations also rise in the DT scenario, but more slowly-by 2100 the concentration is only $556 \mathrm{ppmv}$, or approximately equal to the 550 ppmv target that many ambitious policy makers have argued should be the long-term goal of climate policy.
Interestingly, greenhouse forcing in the DT scenario remains high - only $20 \%$ less intense than in the baseline scenario. High sulfur in the baseline scenario masks nearly half the greenhouse forcing from carbon dioxide. The ratio of sulfur to carbon drops to one-tenth that of the baseline scenario as coal is nearly extinguished from the economy.

Table 3 summarizes the salient characteristics of the IS92a scenario and our baseline and DT scenarios. 
Obviously the results of our model, including the DT scenario, depend on the assumptions that drive the models. For example, the decentralized energy future in the DT scenario, in contrast with the centralized grid-based electricity system of today, is not the only possibility. Here we intend only to illustrate a simple but crucial point: plausible changes in the treatment of technology can yield models and scenarios with dramatically different environmental projections. Whereas other macro models have induced technological change through resource constraints, our approach is more consistent with the emerging view that fossil resources are abundant. Technological changes, in our view, emerge from new demands for energy services, which creates incentives for innovation and application in niche markets, which lead to rapid learning and declining costs; in turn, less costly new technologies diffuse into widespread use.

In our DT scenario, as in history, radically new technologies emerge and dominate on the timescale of a century, often with dramatic changes in environmental worries. In our view the future environmental problems may be less with carbon, sulfur and other externalities of fossil fuels and more with the problems (if any) of hydrogen and electricity energy carriers.

In sum, the use of a technology systems model can help to ensure that the computed future primary and end use energy technologies are internally consistent. A hydrogen economy, for example, must include a compatible hydrogen technology cluster - generation and transport technologies as well as end-use fuel cells and other consumers of hydrogen fuel. Although full endogenous macro scale modeling of technological change is still elusive, our view is that the most promising direction towards that goal is to build models that resolve the building blocks of individual technologies and their interdependencies. Alternative approaches - such as AEEI and other aggregate trend parameters applied to models that have been tuned to present conditions - do not resolve individual technological choices. At best, they are adequate only over short time horizons during which technological change consists predominantly of incremental adjustments to technologies that already exist in the market place (3-4 decades for energy technology systems). Over the longer periods that are characteristic of global change, that approach is inadequate unless (by chance) the aggregate qualities of the new system are like the old. We have shown that some aggregate trends have extended over many successive energy infrastructures. Gradual decarbonization, for example, is evident over two centuries during which more than three energy infrastructures have been in place. Yet even in with that aggregate indicator, existing modeling approaches yield inconsistent results over long time periods because they fail to resolve individual technologies and technological clusters. The IIASA approach shows a way forward, but it does not solve all extant problems. Notably, radical inventions - the building blocks of future radically different technological clusters - remain difficult to project.

\section{Conclusions}

Across a wide range of intellectual and political views one view is shared: in the long run, technology is the factor that most governs growth of the economy, the cost and availability of services such as mobility and food, and the impacts on the environment. Some herald technological innovation as the savior against ecological destruction while others view it as the extension of what caused ecological concerns. Examining the role and sources of technological change, and analyzing potential policies, requires coherent concepts, historical data sets, and models that have not been much applied in the debate over the environmental effects of technology and technological change.

Since technological change is crucial, analytical techniques must be improved. The analysis here suggests at least six findings.

First, while progress on technological analysis has been enormous, much remains to be done. The crucial process of invention, especially the invention of radical technologies, remains largely opaque to systematic analysis. Perhaps an even greater inadequacy of existing techniques, which might be more tractable to solve, is to identify how inventions are selected for commercial investments. The most critical shifts in energy technology, such as the rise of wood- and coal-powered railroads or the emergence of the automobile, can be identified historically, but robust identification of future technological regimes is poor. Most key technologies in the next era are probably found in the marketplace today, but at low levels of penetration; identifying them, and the cluster they comprise, remains beyond existing techniques. In the absence of techniques for perfect forecasting, creative scenario writing and continued debate on alternative futures must continue as the principle means to analyze alternative technological futures.

Second, several patterns in the changing properties of technologies can be identified in the historical record, and these can greatly aid in the modeling of technological change. Learning curves, and characteristic learning rates, can be identified for many technologies. Such curves characterize the expected decline in cost due to investments. We suggest that such curves should be modified to include not only commercial investments - "learning by doing", which begins in niche markets - but also RD\&D that is crucial during the earlier innovation stage. The result is a convenient formulation that allows improved endogenous modeling of technological change. We demonstrate both micro and macro model applications. 
Third, also evident in the historical record are predictable patterns and rates of technological diffusion, which can help modelers estimate the rate and character of change once a technology has entered the marketplace. In general, diffusion and substitution of compatible technologies within an existing technological system or infrastructure occurs more rapidly (time constants of one to two decades) than diffusion of infrastructures and the technologies that are clustered together with numerous other technologies and infrastructures (5 to 10 decades). These time constants can be applied in simple but powerful logistic models of substitution and diffusion.

Fourth, clusters of compatible technologies are evident in the historical record. Such clusters help determine rates of diffusion and which technologies survive from invention to the commercial marketplace. The co-evolution of technologies in clusters becomes more intense as the cluster ages and synergies of compatible technologies deepen. Such co-evolution is evident not only in particular technologies but also the fuels that supply primary energy. The dominant fossil fuels have become progressively lighter in carbon and thus decarbonization is evident as a continuous, long-term historical phenomenon. In the United States, as for the world as a whole, the fuel mix is decarbonizing at approximately $0.3 \%$ per year.

Fifth, it is feasible to solve the non-convex, stochastic problems that result when modeling the (uncertain) increasing returns resulting from learning processes. In our view the causal mechanisms for technological change are investments (RD\&D and learning by working with infant technologies in commercial niche markets) that are made for two reasons - expectation that new technologies will be more competitive, and to hedge against many uncertain risks, including the risk that investments into new technologies will not yield expected improvements in cost and performance. A simple model that includes those drivers - expected cost reductions and uncertainty - yields S-shaped patterns of technological dynamics that are consistent with the historical record. With plausible assumptions, the model endogenously generates radical departures from existing technological practices - a zero carbon future without policy constraints on carbon, and even more rapid decarbonization when modest and uncertain carbon constraints are included. Neither outcome is the result of resource constraints, which is the main mechanism for radical change in conventional models that do not endogenize the process of technological change. We do not contend that the carbon problem will thus autonomously solve itself. But the model outputs underscore that new technologies can penetrate the market even if they are initially a factor of 40 (or more) more expensive than the existing dominant technology. The model suggests that a strategy of investing in radical technologies is socially rational and optimal when risks must be diversified, especially when there is even a small probability of a significant emissions constraint in the future. If the model included the varied other benefits of diversification and the costs of environmental problems such as urban smog which are caused by the same processes that cause carbon emissions, the estimated benefits of diversification should grow further

Sixth, we have also demonstrated that it is possible to include a stylized representation of technological change in macro scale models of the world's energy system. Doing so requires coupling traditional macroeconomic models with models that allow more detailed representation of technological choice - failure to do so forces the modeler to include only gradual and aggregate patterns of technological change (or implausible parameters for sudden, discontinuous radical technological change). Thus conventional models, which are widely used for developing the scenarios that are employed in policy analysis of global change, typically project that the future will be much like the present. Coal retains a high (even increasing) share of primary energy, and carbon emissions are thus also high. In contrast, a coupled model - which we illustrate here - can plausibly yield technological dynamics and lower carbon emissions. Our approach still does not fully endogenize technological change at a macro scale, but conceptually that is now possible. Computational and mathematical bottlenecks should soon be solvable.

These six findings strongly suggest that existing baseline scenarios, which are widely used as the starting point for policy analysis, are incompatible with historical experience, notably decarbonization. (Those scenarios do not have sufficient resolution to determine whether they are incompatible with learning, S-shaped technology dynamics, and co-evolution of technological clusters, all of which are also evident in the historical record.) For future scenarios, the burden is on modelers to justify such sharp deviations from historical experience.

Finally, we offer a few speculations on the policy implications of this work. Our intention has been to show that substantially improved treatment of technological change is possible and mandatory for improved policy analysis. Although we have not analyzed specific policies, our analyses underscore several facts that are relevant for current policy debates. In particular, normal technological dynamics are yielding decarbonization, but at a rate that is slower than the rise in demand for carbon-based fossil fuels. Thus, overall, carbon emissions are rising, but less rapidly than the growth of primary energy consumption. Studies of future energy technologies should take more seriously the need to analyze the technologies that will be in place the future, not to assume that the future will look much like the present. Those future technologies surely include variants of the present vintage, but they are also likely to include many others, including low carbon technologies that are already entering the market through normal technological dynamics that are occurring even without significant constraints on carbon. Thus 
the policy task may be less to promote zero carbon technologies from the laboratory bench to the market and more to explore ways to ensure that network effects enhance rather than bar those low-carbon technologies that on their own will become innovations and commercialized in niche markets.

The results from the micro-level and global optimization models suggest that when confronted with uncertainties - such as whether stringent action to slow global warming or other environmental externalities will be needed - that it is socially rational to diversify technologies. But in market societies, decisions are principally made by market agents rather than social optimizers; those agents respond to individual rather than social incentives. That fact has long justified social (e.g., government) policy to promote research. Insofar as societies today increasingly consider the likely the need for longterm constraints on carbon they should focus attention on incentives to diversify the portfolio of especially radical technologies that will be required if it proves necessary to cut carbon emissions sharply in the future. As we have shown, there is some chance that, by surprise, those technologies will emerge autonomously. It is plausible to project a century-long transition to a practically zero carbon emissions that appears to eliminate (today's) fears about energy-related externalities without any cost. But it remains difficult to assess the probability of such positive surprises, or of their negative counterparts. It is clear that increasing the probability that markets will select technologies with particular characteristics requires not only investment into invention but also more costly investments that carry inventions through development and early demonstration in commercial niche markets. Because the benefits of those investments accrue publicly and globally, technology policy for global change is a global public goods problem. To date, nations have used devices such as treaties to coordinate policies to limit emissions that cause environmental externalities, which has indirectly coordinated technology policy. But a frontal approach to global change problems may require more direct attention to technology policy.

\section{Acknowledgements}

This work is based on the authors' long association with the International Institute for Applied Systems Analysis (IIASA) in Laxenburg, Austria. We thank our colleagues Yuri Ermoliev, Andrei Gritsevskii, and Sabine Messner for contributing to work on which this paper is based. We hope that they will absolve us from any misrepresentations in methods and ideas developed jointly. We also benefited from discussions at the IIASA seminar on induce technological change held June, 1997.

\section{References}

Abramovitz, M., 1993. The search for the sources of growth: areas of ignorance, old and new. Journal of Economic History 52 , 217-243.

Alcamo, J., Bouwman, A., Edmonds, J., Grubler, A., Morita, T., Suganddhy, A., 1994. An evaluation of the IPCC IS92 emission scenarios. Climate Change 1994, Reports of Working Group I and III of the IPCC. Cambridge University Press, Cambridge, pp. 251-305.

Anderson, A.E, Isard, W., Puu, T., 1984. (Eds.), Regional and Industrial Development: Theories, Models and Empirical Evidence. Elsevier, Amsterdam

Argote, L., Epple, D., 1990. Learning curves in manufacturing. Science 247, 920-924.

Arrow, K., 1962. The economic implications of learning by doing. Review of Economic Studies 29, 920-924

Arthur, W.B., 1983. On competing technologies and historical small events: the dynamics of choice under increasing returns. Working Paper 83-90, International Institute for Applied Systems Analysis, Laxenburg, Austria.

Arthur, W.B., 1989. Competing technologies, increasing returns, and lock-in by historical events. The Economic Journal 99, 116-131.

Astakhov, A., Grübler, A., Mookhin, A., 1990. Technology diffusion in the coal-mining industry of the USSR: an interim assessment. Technological Forecasting and Social Change 50, 113-134.

Ausubel, J.H., Grüebler, A., Nakićenović, N., 1988. Carbon dioxide emissions in a methane economy. Climatic Change 12, 245-263.

Ausubel, J.H., Marchetti, C., 1996. Elektron: electrical systems in retrospect and prospect. Daedalus 125, 139-169.

Barnett, H.J., Morse, C., 1967. Scarcity and Growth: The Economics of Natural Resource Availability. Johns Hopkins Press, Baltimore.

Binswanger, H.P., 1978. Induced technical change: evolution of thought. In: Binswanger, H.P., Ruttan, V.W. (Eds.), Induced Innovation: Technology, Institutions and Development. Johns Hopkins University Press, Baltimore, pp. 13-43.

Brooks, H., 1986. The typology of surprises in technology, institutions, and development. In: Clark, W.C., Munn, R.E. (Eds.), Sustainable Development of the Biosphere. Cambridge University Press, Cambridge, pp. 325-348

Buttner, T., Grübler, A., 1995. The birth of a 'Green' generation? generational dynamics of resource consumption patterns. Technological Forecasting and Social Change 50, 113-134.

Cantley, M.F., Sahal, D., 1980. Who learns what? a conceptual description of capability and learning in technological systems. Research Report 80-42. International Institute for Applied Systems Analysis, Laxenburg, Austria.

Christiansson, L., 1995. Diffusion and learning curves of renewable energy technologies. Working Paper 95-126. International Institute for Applied Systems Analysis, Laxenburg, Austria.

Cowan, R., 1991. Tortoises and hares: choice among technologies of unknown merit. The Economic Journal 101, 801-814.

David, P., 1985. CLIO and the economics of QWERTY. American Economic Review 75, 332-337.

Ermoliev, Y., Wets, R. (Eds.), 1988. Numerical Techniques for Stochastic Optimization. Computational Mathematics. Springer, Berlin.

Fisher, J.C., Pry, R.H., 1971. A simple substitution model of technological change. Technological Forecasting and Social Change 3, 75-88.

Fragnière, E., Haurie, A., 1995. A stochastic programming model for energy/environment choices under uncertainty. International Journal of Environment and Pollution, 6, 587-603.

Frankel, M., 1955. Obsolescence and technological change in a maturing economy. American Economic Review 45, 296-319.

Freeman, C., 1982/1989. The Economics of Industrial Innovation, 2nd ed. MIT Press, Cambridge. 
Freeman, C., 1994. The economics of technical change. Cambridge Journal of Economics 6, 587-603.

Goldnikov, A., Gritsevskii, A., Messner, S., 1995. A stochastic version of the dynamic linear programming model MESSAGE III. Working Paper 95-94. International Institute for Applied Systems Analysis, Laxenburg, Austria.

Goulder, L., Schneider, S., 1996. Induced technical change, crowding out, and the attractiveness of $\mathrm{CO} 2$ emissions abatement. Stanford University, Stanford, Mimeo.

Griliches, Z., 1996. The discovery of the residual: a historical note Journal of Economic Literature 34, 1324-1330.

Grübler, A., 1990. The Rise and Fall of Infrastructures. Physica Verlag, Heidelberg.

Grübler, A., 1991. Diffusion: long-term patterns and discontinuities. Technological Forecasting and Social Change 39, 159-180.

Grübler, A., 1996. Time for a change: on the patterns of diffusion of innovation. Dédalus $125,19-42$

Grübler. A., 1998. Technology and Global Change. Cambridge University Press, Cambridge.

Grübler, A., Gritserskii. A., 1997. A model of endogenous technological change through uncertain returns on learning (R\&D and Investments). Economic Journal (submitted)

Grübler, A., Nakićenović, N., 1991. Long waves, technology diffusion and substitution. Review 14, 313-342.

Grübler, A., Nakicenović, N., 1996. Decarbonizing the global energy system. Technological Forecasting and Social Change 53, 97-110.

Grübler, A, Nakićenović. N., Posch. M., 1988. Methods for estimating S-shaped growth functions: algorithms and computer programs. International Institute for Applied Systems Analysis, Laxenburg, Austria, Mimeo.

Ha-Duong. M., Grubb, M.J., Hourcade. J.-C., 1997. Influence of socioeconomic inertia and uncertainty on optimal $\mathrm{CO}$-emission abatement. Nature 390, 270-273.

Hägerstrand, T., 1967. Innovation Diffusion as a Spatial Process. University of Chicago Press. Chicago.

Hammitt, J.K., Lempert. R.J., Schlesinger, M.E., 1992. a sequentialdecision strategy for abating climate change. Nature 357, 315-318.

Hayami. Y., Ruttan, V., 1985. Agricultural Development: An International Perspective, 2nd ed.. Johns Hopkins Press, Baltimore.

Holling. C. S., 1978. Adaptive Environmental Assessment and Management. Wiley, Chichester

Hughes. T.P. 1983. Networks of Power: Electrification in Western Society 1880-1930. John Hopkins Press, Baltimore.

Isurd. W. 1942. A neglected cycle: the transport building cycle. Review of Economics and Statistics 24, 149-158.

Jorgenson. D.W.. Fraumeni. B.M., 1981. Relative prices and technical change. In: Bendt. E., Fields. B. (Eds.). Modeling and Measuring Natural Resource Substitution. MIT Press, Cambridge.

Kolstad, C.D. 1993. Looking vs. leaping: the timing of $\mathrm{CO}_{2}$ control in the face of uncertainty and learning. In: Kaya, Y., Nakicenovic, N., Nordhaus, W.D., Toth. F. L. (Eds.), Costs, Impacts, and Benefits of $\mathrm{CO} 2$ Mitigation. International Institute for Applied Systems Analysis (CP-93-2). Laxenburg. Austria, pp. 63-82.

Lakatos. I.. 1970. Falsification and the methodology of scientific research programmes. In: Lakatos, I., Musgrave, A. (Eds.), Criticism and the Growth of Knowledge. Cambridge University Press, Cambridge.

Lazarus, M. et al., 1993. Towards a Fossil Free Energy Future: The Next Energy Transition. Stockholm Environmental Institute, Boston.

Lempert. R.J.. Schlesinger. M.E., Bankes. S.C., 1996. When we don't know the costs or the benefits: adaptive strategies for abating climate change. Climatic Change 33, 235-274.

Lotka, A., 1924. Elements of Physical Biology, reprinted., 1956). Elements of Mathematical Biology. Dover Publishers, New York.

MacGregor. P.R., Maslak, C.E., Stoll, H.G., 1991. The market outlook for integrated gasification combined cycle technology. Proceeding of International Exhibition and Conference for the Power Generation Industries - Power-Gen 7-8, 1298-1325.

Maddison, A., 1991. Dynamic Forces in Capitalist Development: A Long-run Comparative View. Oxford University Press, Oxford.

Maddison, A., 1995. Monitoring the World Economy 1820-1992, OECD Development Centre Studies, OECD, Paris

Manne, A.S., Richels, R.G., 1992. Buying Greenhouse Insurance: The Economic Costs of Carbon Dioxide Emission Limits. MIT Press, Cambridge.

Manne, A., Richels, R., 1994. The cost of stabilizing global $\mathrm{CO}_{2}$ emissions: a probabilistic analysis based on expert judgement. The Energy Journal, 15, 31-56.

Manne, A., Richels, R., 1997. Modeling endogenous technology diffusion in MERGE 3. Paper presented at the Conference on Induced Technical Change and the Environment. International Institute for Applied Systems Analysis, Laxenburg, Austria, 26-27 June 1997.

Mansfield, E., 1961. Technical change and the rate of imitation. Econometrica 29, 741-766

Mansfield, E., 1968. The Economics of Technological Change. W.W Norton, New York.

Mansfield, E., 1985. How rapidly does new industrial technology leak out? Journal of Industrial Economics 34, 217-223.

Mansfield, E., Rapoport, J., Romeo, A., Villani, E., Wagner, S., Husic. F., 1977. The Production and Application of New Industrial Technology. W.W. Norton, New York

Mansfield, E., Rapoport, J., Schnee, J., Wagner, S., Hamburger, M., 1972. Research and Development in the Modern Corporation. Norton, New York.

Marchetti, C., 1980. Society as a learning system - discovery, invention and innovation cycles revisited. Technological Forecasting and Social Change 18, 267-282.

Marchetti, C., 1983. The automobile in a systems context. Technological Forecasting and Social Change 23, 3-23.

Marchetti, C., 1988. The future of natural gas: a darwinian analysis. In: Lee, T.H., Linden, H.R., Dreyfus, D.A., Vasko, T. (Eds.), The Methane Age. Kluwer, Dordrecht.

Marchetti, C., Nakicenovic, N., 1979. The dynamics of energy systems and the logistic substitution model. Research Report 79-13, International Institute for Applied Systems Analysis, Laxenburg. Austria.

Meadows, D.H. Meadows, D.L., Randers, J., Behrens, W.W.. 1972. The Limits to Growth. A Report for the Club of Rome's Project on the Predictament of Mankind. Signet, New York.

Meadows, D.H., Meadows, D.L., Randers, J., 1992. Beyond the Limits: Global Collapse or a Sustainable Future? Earthscan, London.

Messner, S., 1996. The CO2DB inventory and its application in a comparative assessment of electricity end use options. Proceedings of a Symposium on Electricity, Health and the Environment: Comparative Assessment in Support of Decision Making Vienna, Austria, International Atomic Energy Agency (IAEA-SM-338/57), 16-19 October 1995.

Messner, S., 1997. Endogenized technological learning in an energy systems model. Journal of Evolutionary Economics 7, 291-313.

Messner, S., Strubegger, M., 1991. User`s Guide to CO2DB: The IIASA $\mathrm{CO}_{2}$ technology data bank, version 1.0. Working Paper 91-31a. International Institute for Applied Systems Analysis, Laxenburg. Austria.

Messner, S., Strubegger, M., 1995. User's Guide for MESSAGE III. Working Paper 95-69. International Institute for Applied Systems Analysis, Laxenburg, Austria.

Messner, S., Golodnikov, A., Gritsevskii, A., 1996. A stochastic version of the dynamic linear programming model MESSAGE III. Energy 21, 775-784.

Metcalfe, S., 1987. Technical change. In: Eatwell, J., Milgate, M. Newman, P. (Eds.), The New Palgrave, A Dictionary of Economics, vol. 4. Macmillan, London, pp. 617-620. 
Meyer, P., 1994. Bi-logistic growth. Technological Forecasting and Social Change 47, 89-102.

Mokyr, J., 1990. The Lever of Riches: Technological Creativity and Economic Progress. Oxford University Press, Oxford.

Montroll, E.W., 1978. Social dynamics and the quantifying of social forces. Proceedings National Academy of Sciences 75, 4633-4637.

Nakićenović, N. 1984. Growth to Limits: Long Waves and the Dynamics of Technology. Dissertation, Vienna, Austria, Sozial- und Wirtschaftswissenschaftliche Fakultät, Universität Wien.

Nakićenović, N., 1986. The automotive road to technological change: diffusion of the automobile as a process of technological substitution. Technological Forecasting and Social Change 29, 309-340

Nakićnović, N., 1990. Dynamics of change and long waves. In: Vasko, T., Ayres, R., Fontvieille, L. (Eds.), Life Cycles and Long Waves. Springer, Berlin, Lecture Notes in Economics and Mathematical Systems, pp. 147-192.

Nakicenovic, N., 1994. Energy gases: the methane age and beyond. The Future of Energy Gases. Washington, DC, US Geological Survey Professional Paper 1570

Nakićenović, N., 1996. Technological change and learning. In: Nakićenović, N., Nordhaus, W.D., Richels, R., Toth, F.L. (Eds.), Climate Change: Integrating Science, Economics and Policy. International Institute for Applied Systems Analysis (CP-96-1), Laxenburg, Austria.

Nakicenovic, N., Amann, M., Fischer, G. principal authors, 1998. Global energy supply and demand and their environmental effects, Tokyo, Final Report to the Central Research Institute of the Electric Power Industry, 28 February 1998

Nakićenovic, N., Grübler, A., Jefferson, M., McDonald, A., Messner, S., Rogner, H.-H., Schrattenholzer, L., 1995. Global Energy Perspectives to 2050 and Beyond, Laxenburg, Austria, International Institute for Applied Systems Analysis, and London, World Energy Council.

Nordhaus, W.D., 1973. The allocation of energy resources. Brookings Papers on Economic Activity 3, 529-576.

Nordhaus, W.D., 1979. The Efficient Use of Energy Resources. Yale University Press, New Haven, (Cowles Foundation Monograph 26).

Nordhaus, W.D., van der Heyden, L., 1983. Induced technical change: a programming approach. In: Schurr, S.H., Sonenblum, S., Wood, D.O. (Eds.). Energy, Productivity, and Economic Growth. Oelgeschlager, Gunn and Hain, Cambridge, MA, pp. 379-404.

Organisation for Economic Cooperation and Development, 1996. Technology and Industrial Performance: Technology Diffusion, Productivity, Employment and Skills, International Competitiveness. OECD, Paris.

Pepper, W., Leggett, J., Swart, R., Wasson. J., Edmonds, J., Mintzer, I., 1992. Emissions Scenarios for the IPCC: an update. prepared for the Intergovernmental Panel on Climate Change, Working Group I, May, 1992.

Rogner, H.-H., 1997. An assessment of world hydrocarbon resources. Annual Review of Energy and the Environment 22, 217-262.

Romer, P.M., 1986. Increasing returns and long-run growth. Journal of Political Economy 94, 1002-1137.

Romer, P.M., 1990. Endogenous technical change. Journal of Political Economy 98, 570-601.
Rosenberg, N., 1982. Inside the Black Box: Technology and Economics Cambridge University Press, Cambridge.

Ruttan, V.W., 1996. Induced innovation and path dependence: a reassessment with respect to agricultural development and the environment. Technological Forecasting and Social Change 53, 41-59.

Schäfer, A., Schrattenholzer, L., Messner, S., 1992. Inventory of greenhouse-gas mitigation measures: examples from IIASA technology data bank. Working Paper 92-85 Laxenburg, Austria, Internationa Institute for Applied Systems Analysis.

Schneider, S.H., Goulder, L.H., 1997. Achieving low-cost emissions targets. Nature 239, 13-14.

Schumpeter, J.A., 1934, transl. of 1912 ed. The Theory of Economic Development. Harvard University Press, Cambridge.

Sobel, D., 1995. Longitude: The True Story of a Lone Genius Who Solved the Greatest Scientific Problem of His Time. Walker, New York.

Solow, R.M., 1957. Technical change and the aggregate production function. Review of Economics and Statistics 39, 312-320.

Starr, C., Rudman, R., 1973. Parameters of technological growth. Science $182,358-364$

Steward, H.B., 1982. Technology Innovation and Business Growth. Nutveco, San Diego.

Strubegger, M., Reitgruber, I., 1995. Statistical analysis of investment costs for power generation technologies. Working Paper 95-109 Laxenburg, Austria, International Institute for Applied Systems Analysis.

United States Department of Commerce, 1975. Historical Statistics of the United States: Colonial Times to 1970, Washington, US DOC, Bureau of the Census (2 volumes).

Teubal, M., Foray, D., Justman, M., Zuscovitch, E. (Eds.), 1996. Technological Infrastructure Policy. Kluwer, Dordrecht.

Tinbergen, J., 1942. Zur Theorie der langfristigen Wirtschaftsentwicklung. Weltwirtschaftliches Archiv 1, 511-549.

Volterra, V., 1927. Una teoria matematica sulla lotta per l'estistenza. Scientia 41, 850-102.

Walters, C.J., 1986. Adaptive Management of Renewable Resources. Macmillan, New York.

Ward, W.H., 1967. The sailing ship effect. Buttelin Institute of Physics and Physics Society 18, 169.

Watanabe, C., 1995. Identification of the role of renewable energy. Renewable Energy 6, 237-274.

Wene, C.-O., 1995. Energy-economy analysis: linking the macroeconomic and systems engineering approachs. Energy-The International Journal 21, 809-824.

Wigley, T.M.L., 1991. A simple inverse carbon cycle model. Global Biogeochemical Cycles 5, 373-382.

Wigley, T.M.L., 1993. Balancing the carbon budget: implications for projections of future carbon dioxide concentration. Tellus $45 \mathrm{~B}$, 409-425.

Wigley, T.M.L., Raper, S.C.B., 1987. Thermal expansion of sea water associated with global warming. Nature 330, 127-131.

Wigley, T.M.L., Raper, S.C.B., 1992. Implications for climate and sea level of revised IPCC emissions scenarios. Nature 357, 293-300.

Wright, T.P., 1936. Factors affecting the costs of airplanes. Journal of the Aeronautical Sciences 3, 122-128. 


\section{ORDERING INFORMATION}

Orders must include the publication number and should be sent to the Publications Department, International Institute for Applied Systems Analysis, A-2361 Laxenburg, Austria.

Telephone: +432236807

Telefax: +43223671313

E-mail: molina@iiasa.ac.at

A full list of IIASA publications is available at http://www.iiasa.ac.at 
International Institute for Applied Systems Analysis

A-2361 Laxenburg, Austria 